\title{
LA EDUCACIÓN DE GÉNEROY DIVERSIDAD SEXUAL, ¿IMPOSICIÓN IDEOLÓGICA U OBLIGACIÓN CONSTITUCIONAL?
}

\section{Education on Gender and Sexual Orientation, Ideological Imposition or Constitutional Obligation?}

\author{
Blanca Orts Torregrosa \\ E-mail: ortsblanca@gmail.com
}

Autor

La educación de género y diversidad sexual en el sistema educativo español es un asunto controvertido y politizado, que tiene lugar solo en determinadas comunidades autónomas a través del desarrollo de leyes autonómicas. En este artículo se trata de dilucidar si la educación en dicha materia constituye una obligación constitucional y no una imposición ideológica o adoctrinamiento por parte de los poderes públicos. En primer lugar, se realiza un análisis del principio de autodeterminación extendido a la identidad de género y la orientación sexual. Secundariamente, se estudia el alcance de la vertiente prestacional del derecho a la educación y su finalidad en contraposición a la libertad de enseñanza. Concretamente, se analizan los resultados de dicha interacción, el principio de neutralidad del Estado en la actividad educativa y la extensión de la objeción de conciencia de los padres. Asimismo, se establece la analogía con la obligatoriedad de la asignatura de Educación para la ciudadanía a través de la proposición de un modelo educativo nacional en materia de identidad de género y orientación sexual basado en las leyes autonómicas existentes. Finalmente, se concluye que la educación de género y diversidad sexual constituye una obligación constitucional que implica una modificación de la programación general de la enseñanza.

The education on gender and sexual orientation within the Spanish educational system is a controverted and politicized issue, and is only implemented in certain Autonomous Regions through the development of regional laws. This paper focuses on determining whether education on gender and sexual orientation is a constitutional obligation or an ideological imposition and an indoctrination by the State. Firstly, it provides an analysis of the principle of self-determination in terms of gender identity and sexual orientation. Secondly, it deals with the extension of the State's educational obligation and its constitutional purpose as opposed to the freedom of education. Specifically, it analyses the principle of the State's neutrality in its educational activity and the scope of parents' right to conscientious objection with relation to the referred interaction. Likewise, it establishes an analogy between a proposed educational model on gender identity and sexual orientation based on the regional approaches, and the compulsory subject of Education for Citizenship. Closing remarks demonstrate the constitutional obligation of the education on gender and sexual orientation, thus implying a reform of the general educational program.

\section{Resumen}


derecho a la educación; identidad de género; orientación sexual; objeción de conciencia; libertad de enseñanza

right to education; gender identity; sexual orientation; conscientious objection; freedom of education

Recibido: 10/05/2021. Aceptado: 20/06/2021

\section{O Key words}

\section{Introducción}

El objeto de estudio de este artículo se centra en el análisis de la naturaleza de la educación de género y diversidad sexual, que se debate entre una obligación constitucional y una imposición ideológica.

Para tratar la discriminación contra la diversidad sexual en España, primero cabe introducir el marco jurídico básico aplicable, para después desarrollar un breve contexto histórico.

La Constitución española de 1978, en su artículo 9, obliga a los poderes públicos a promover las condiciones para que la libertad e igualdad del individuo y de los grupos sociales en los que se integra sean reales y efectivas, con remoción de los obstáculos que llevan a su plenitud. El artículo 10 procede a desarrollar brevemente estos valores de referencia, la dignidad de la persona, los derechos inviolables que le son inherentes, el libre desarrollo de la personalidad, el respeto a la ley y a los derechos de los demás son fundamento del orden político y de la paz social. Por último, el artículo 14 reconoce la igualdad de los españoles ante la ley, sin que pueda prevalecer discriminación alguna por razón de nacimiento, raza, sexo, religión, opinión o cualquier otra condición o circunstancia personal o social.

Continuando con la Constitución, el artículo 10, en su apartado segundo, matiza que las normas relativas a los derechos fundamentales se interpretarán conforme con la Declaración Universal de Derechos Humanos y los tratados y acuerdos internacionales en dichas materias ratificados por España. A tal efecto, en el artículo 2 de la Declaración Universal de Derechos Humanos se reconoce que todas las personas tienen los mismos derechos y libertades. En el elenco de derechos se afirma que la condición sexual no pude suponer distinción alguna en el uso y disfrute de los derechos. Por otra parte, el Consejo de Derechos Humanos, en su Resolución 17/19 de 2011, condena cualquier acto de violencia o discriminación por orientación sexual e identidad de género. Esta prohibición se recoge también en el artículo 21 de la Carta de Derechos Fundamentales de la Unión Europea.

Con respecto a la discriminación contra la diversidad sexual, procede comenzar con la dictadura franquista y el inicio de la actual democracia. En este periodo, las personas homosexuales, bisexuales y transexuales eran sujeto de detención y encarcelamiento por su orientación sexual. Más concretamente, en 1954 se reforma la Ley de Vagos y Maleantes de 1933 para equiparar a los homosexuales, sancionándoles como a los proxenetas, mendigos, enfermos mentales o lisiados. Para la reforma de los maleantes, entre los que se encuentran los homosexuales, desde la finalidad protectora del Estado, se les internaba en un establecimiento de trabajo o Colo- 
nia Agrícola. En cualquier caso, los homosexuales sometidos a esta medida eran internados en Instituciones Especiales y con absoluta separación de los demás. Años más tarde, la Ley de peligrosidad social, de 1970, que sustituye a la Ley de Vagos y Maleantes de 1933, sustituía el internamiento en Instituciones Especiales por los establecimientos de reeducación para aquellos que realizasen actos de homosexualidad, manteniendo la prohibición de residencia y visita de determinados lugares. El internamiento en los establecimientos de reeducación implicaba un denominado "tratamiento" que podía incluir lobotomía y descargas eléctricas. Esta última Ley no eliminó la mención a "los actos de homosexualidad" hasta enero del año 1979 y fue derogada completamente el 23 de noviembre de 1995. A pesar de esto, se mantenían las persecuciones a las personas lesbianas, gais, bisexuales y transgénero (en adelante, LGBT) a través de la figura de la Ley de Escándalo Público, no modificada hasta 1983 y derogada en 1989. Pese al cese de estas persecuciones, en el año 2013 la orientación o identidad sexual se registra como la causa del mayor número de delitos de odio, por encima del racismo y la xenofobia (Secretaría de Estado de Seguridad, 2013). Finalmente, a fecha de 2018 los delitos de odio con motivo de orientación sexual representan el $28 \%$ del total de los casos y la segunda causa de delitos de odio en España (Dirección General de Servicios Sociales e Integración Social Comunidad de Madrid, 2018).

En suma, la discriminación contra la diversidad sexual cobra especial trascendencia en relación con la importancia vehicular de la educación en la configuración de la sociedad. El derecho a la educación y la libertad de enseñanza juegan un papel esencial en la sociedad democrática y de derecho, en la convicción de que de ellos dependen el bienestar individual y colectivo. La finalidad de la educación presenta dos vertientes, de carácter individual o subjetivo, en tanto que su objetivo es el pleno desarrollo de la personalidad humana, y de carácter objetivo como herramienta que configura la sociedad. La educación es el medio más adecuado para construir la personalidad del individuo, desarrollar sus capacidades y conformar su identidad personal. Asimismo, mediante la educación se transmiten un conjunto de valores y principios que constituirán el mínimo acervo común de todos los ciudadanos, conformando así la infraestructura sobre la que se sustentan la convivencia democrática y el respeto a los derechos fundamentales. Partiendo del objetivo fundamental de lograr la cohesión social, la educación se convierte en el vehículo más adecuado para impulsar el respeto al libre desarrollo de la personalidad y la consecuente diversidad, fomentar la solidaridad y reducir la discriminación.

Para determinar la obligatoriedad constitucional de la educación de género y diversidad sexual seguiré la siguiente estructura lógica.

En el primer epígrafe, trataré el principio de autodeterminación y el derecho al libre desarrollo de la personalidad del artículo $10 \mathrm{CE}$ en materia de identidad de género y orientación sexual, así como la correspondiente titularidad de los niños, que sentará la base constitucional de los epígrafes subsiguientes.

Secundariamente, en el segundo epígrafe, desarrollaré el derecho a la educación del artículo $27 \mathrm{CE}$ y la finalidad establecida por el constituyente en esta materia. Analizaré cómo la educación se constituye como un vehículo para la construcción de la identidad y el pleno desarrollo de la personalidad. Finalmente, observaré la vivencia práctica actual y el grado de cumplimiento de los objetivos establecidos en el sector educativo.

En tercer lugar, analizaré la libertad de enseñanza a través de los derechos en que se vertebra: la creación de centros docentes, la libertad de cátedra, el derecho de los padres a elegir la formación religiosa y moral para sus hijos, y la intervención de los profesores, los padres y los 
alumnos en la gestión de los centros sostenidos por la Administración con fondos públicos. Por último, expondré las conclusiones extraídas del presente estudio y contestaremos a la pregunta que se planteaba inicialmente: la educación de género y diversidad sexual, ¿imposición ideológica u obligación constitucional?

\section{Derecho a la autodeterminación. Identidad de género y diversidad sexual}

\subsection{El principio de autodeterminación de la personalidad}

En este apartado estudiaré el principio de autodeterminación de la personalidad del artículo 10 de la Constitución Española (en adelante, CE), para interpretarlo en conjunción con el artículo 27 CE en el epígrafe siguiente y, de esta manera, delimitar el contenido de la dimensión subjetiva de la finalidad del derecho a la educación.

El artículo 10 CE, que abre el Título I de la Constitución, de los Derechos y Deberes Fundamentales, reza: "La dignidad de la persona, los derechos inviolables que le son inherentes, el libre desarrollo de la personalidad, el respeto a la ley y a los derechos de los demás son fundamento del orden político y la paz social”.

Así la primera rúbrica del artículo 10, "la dignidad de la persona", constituye el derecho y principio fundamental que inspira el resto del Título I. A través de la jurisprudencia del Tribunal Constitucional, se define la dignidad como valor espiritual y moral inherente a la persona, "que se manifiesta singularmente en la autodeterminación consciente y responsable de la propia vida y que lleva consigo la pretensión al respeto por parte de los demás” (STC 53/1985, de 11 de abril, F.J.3). Añadido a esto, "la dignidad ha de permanecer inalterada cualquiera que sea la situación en que la persona se encuentre, [...] constituyendo, en consecuencia, un mínimum invulnerable que todo estatuto jurídico debe asegurar" (SSTC 120/1990, de 27 de junio, F.J.4; 57/1994, de 28 de febrero, F.J.3).

El fundamento de la configuración de la dignidad de la persona como valor superior del ordenamiento jurídico se basa en: la dignidad superior a nivel cualitativo del ser humano en comparación con el resto de los seres, la inadmisión de la gradación de la dignidad y la imposibilidad de su devaluación dependiente del individuo o el grupo de personas. Asimismo, la dignidad opera como fundamento del que derivan los Derechos positivos estatales y el Derecho internacional, dada la necesidad de la adecuación de sus preceptos a esta primera. Finalmente, la dignidad es irrenunciable, inalienable e indisponible hasta la terminación de la vida (Merino Noverto, 2003).

No obstante, la dignidad como valor superior del ordenamiento jurídico alcanza la totalidad de su trascendencia en sus manifestaciones prácticas, concretamente a través del postulado del "libre desarrollo de la personalidad" y la "autodeterminación consciente y responsable de la propia vida” (STC 53/1985, de 11 de abril, F.J.3).

Desde el plano jurídico-filosófico, según la concepción moderna, la autonomía deriva de la libertad indeterminada, que se basa en la naturaleza racional del ser humano, fundamento de su dignidad. Como argumentaba Kant, ser autónomo significa actuar según un marco de reglas que uno se da a sí mismo (Oshana, 1998), o con arreglo a sus propias convicciones y 
mantenerlas frente a terceros (STC 154/2002, de 18 de julio). La autodeterminación asume la comprensión de los valores que manejan los diferentes agentes en sociedad, su discernimiento y la consecuente capacidad de regir la vida personal conforme a valores fruto de elaboración personal (Segovia, 2020). Gerald Dworkin arguye que la condición para la validación de la autonomía del individuo es la independencia e indeterminación de sus valores respecto de aquellos esgrimidos por sus padres, compañeros y entidades apolíticas como los medios de comunicación, la opinión pública y las instituciones financieras. Según Dworkin, la existencia de estos factores no depende de la elección del individuo, sino que simplemente se enfrenta a ellos, por lo que no existiría un punto de partida de indeterminación. Por ello, aporta una definición de autonomía que salva esta dificultad, afirmando que se trata de la capacidad de las personas para reflexionar críticamente sobre sus preferencias, anhelos y necesidades primarias, y la capacidad de aceptar o cambiar estas según preferencias o valores ulteriores (Dworkin, 1997 [1988]). Si escalamos la autodeterminación y la autonomía individual, estas cobran sentido en el plano colectivo a través de la interacción del liberalismo y la democracia. El Estado democrático otorga derechos bajo el presupuesto de la capacidad autolegislativa del pueblo, configurando la autodeterminación política estatal, véase artículos 1.2 y 66.1 y $2 \mathrm{CE}$. Añadido a esto, si escalamos el principio de autodeterminación a todos los individuos que integran un Estado, esto conduciría a la construcción de múltiples identidades minoritarias. James Tully arguye que la fragmentación de la sociedad en estas identidades puede derivar en un enfrentamiento social, dada la variedad en las formas de autonomía. Para solucionar esto, propone un "constitucionalismo de la diversidad cultural de los ciudadanos" (Tully, 1995). En definitiva, el enfrentamiento social se produce únicamente a través del discurso en las correspondientes cámaras legislativas, ya que la democracia implica la aceptación de la doctrina del consenso mayoritario y el otorgamiento de derechos fundamentales inviolables a todos los individuos, sin perjuicio de su fragmentación en minorías a través de la autodeterminación de su identidad.

El análisis holístico del derecho al libre desarrollo de la personalidad que proclama el artículo 10 CE exige, según su apartado segundo, su interpretación conforme a la Declaración Universal de Derechos Humanos y los tratados y acuerdos ratificados por España. Esto obliga a la interpretación de los preceptos según las estipulaciones de los Tratados o Convenios (STC 36/1995, de 14 de febrero, F.J.5). En este sentido, son especialmente relevantes para el contenido y la extensión del principio de autodeterminación y el derecho al libre desarrollo de la personalidad: el Convenio para la protección de los Derechos Humanos y de las Libertades fundamentales, hecho en Roma el 4 de noviembre de 1950 (en adelante, CEDH), y su intérprete, el Tribunal Europeo de Derechos Humanos (en adelante, TEDH). El CEDH en su artículo 8 proclama: "Toda persona tiene derecho al respeto de su vida privada y familiar". El TEDH ha definido vida privada como el espacio regido por la autonomía individual libre de intrusión (Merino Sancho, 2018). A través de la jurisprudencia, el TEDH ha reconocido de forma incremental diversas nociones que extienden el derecho a la vida privada y, por lo tanto, la protección brindada por el artículo 8 . Entre dichas nociones distinguimos la integridad física y psicológica del individuo (STEDH 8978/80, Caso Xe Yc. Reino de los Países Bajos, de 26 de marzo de 1985), la identidad de género (STEDH 13343/87, Caso B c. Francia, de 25 de marzo de 1992), la identidad física, ética y social (STEDH 53176/99, Caso Mikulicc. Croacia, de 7 de febrero de 2002), y la orientación y la vida sexual (STEDH 7525/76, Caso Dudgeon c. Reino Unido, de 22 de octubre de 1981). Asimismo, el artículo 8 CEDH protege el derecho al desarrollo personal, así como el establecimiento de relaciones con otros seres humanos y el resto del mundo (STEDH 13710/88, Caso Niemietz c. Alemania, de 16 de diciembre de 1992). 
En suma, el derecho a la autonomía individual emana de los artículos 3 y $8 \mathrm{CEDH}$, de la dignidad de la persona y del derecho a la vida privada (Rudolf, 2003). Según los precedentes establecidos por el TEDH, la noción de autonomía individual opera no solo como un principio que guía la interpretación de sus preceptos y garantías (STEDH 2346/02, Caso Pretty c. Reino Unido, de 29 de abril de 2002), sino también como un derecho en sí mismo (SSTEDH 6339/05, Caso Evansc. Reino Unido, de 10 de abril de 2007 y 5410/03, Caso Tysiac c. Polonia, de 20 de marzo de 2007).

\subsection{La identidad de género y la orientación sexual}

La identidad de género constituye, por tanto, un factor de la autonomía personal sobre el que el individuo tiene derecho a determinarse y pronunciarse (STEDH 13343/87, Caso B c. Francia, de 25 de marzo de 1992). Pero, ¿cuáles son el alcance y el sentido de la identidad de género? La identidad de género es uno de los aspectos fundamentales de la construcción de la personalidad. El sexo de una persona se asigna en el momento de su nacimiento y desde entonces se constituye como un hecho social y jurídico. No obstante, un pequeño grupo de personas experimenta problemas con la identificación del sexo asignado al nacer. Este problema se plantea en el caso de las personas intersexuales, que muestran caracteres anatómicos o fisiológicos pertenecientes a ambos sexos, masculino y femenino. Asimismo, se plantea para aquellas personas cuya percepción de su género no coincide con el sexo que se les asigna al nacer. Estas personas son tratadas como transgénero o transexuales. Para entender el concepto de identidad de género, es importante establecer la distinción entre sexo y género. Mientras que el sexo se refiere fundamentalmente a las diferencias biológicas entre hombres y mujeres, el género incluye los aspectos sociales de la diferencia entre ambos sexos, añadidos a las diferencias biológicas (Commissioner for Human Rights, 2009). Según los Principios de Yogyakarta, sobre la Aplicación de la Legislación Internacional de Derechos Humanos en Relación con la Orientación Sexual y la Identidad de Género y la Agencia de Derechos Fundamentales de la Unión Europea, la identidad de género hace referencia a la "vivencia interna e individual del género tal como cada persona la siente profundamente, la cual podría corresponder o no con el sexo asignado al momento del nacimiento, incluyendo la vivencia personal del cuerpo (que podría involucrar la modificación de la apariencia o la función corporal a través de medios médicos, quirúrgicos o de otra índole, siempre que la misma sea libremente escogida) y otras expresiones de género, incluyendo la vestimenta, el modo de hablar y los modales".

Por otra parte, con la orientación sexual se trata de la capacidad de cada persona para desarrollar atracción afectiva, física y emocional profunda, y relaciones sexuales e íntimas con individuos del mismo sexo, distinto sexo o ambos (homosexualidad, heterosexualidad, y bisexualidad).

\subsection{Autodeterminación y libre desarrollo de la personalidad en materia de identidad de género y orientación sexual}

Tras la revisión del contenido de los conceptos de identidad de género y orientación sexual, analizaré ahora los argumentos esbozados por la jurisprudencia del TEDH, el Tribunal Constitucional y el Tribunal Supremo en los casos donde se extiende la protección del principio de autodeterminación y el libre desarrollo de la personalidad a estos factores. 
Como hemos tratado anteriormente, el TEDH se pronuncia sobre la cuestión de la identidad de género en la STEDH 13343/87, Caso B c. Francia, de 25 de marzo de 1992, donde resuelve que la necesidad de identificación por medio de documentos oficiales que señalan el sexo impide el desenvolvimiento del transexual en la vida diaria sin descubrir la discordancia entre su sexo legal y aparente. Este inconveniente resulta suficientemente gravoso para considerarlo una situación global incompatible con el derecho a la vida privada protegido por el artículo 8 CEDH. Añade el TEDH en las SSTEDH 28957/95, Caso Christina Goodwin c. Reino Unido, de 11 de julio de 2002, que este conflicto entre la realidad social y el derecho "coloca a la persona transexual en una situación anormal que le provoca sentimientos de vulnerabilidad, humillación y ansiedad". En definitiva, el TEDH concluye que, en el siglo XXI, que los transexuales gocen del derecho al desarrollo personal y la integridad física y moral no puede ser un asunto controvertido. La noción de vida privada extendida a la identidad de género, la orientación y la vida sexual, así como al "derecho a establecer y consolidar relaciones con otros seres humanos y con el entorno que le rodea" aplicada a las personas transgénero, implica "derecho a la autodeterminación” (SSTEDH 79885/12, 52471/13, 52596/13, A.P. Caso Garçon y Nicot c. Francia, de 6 de abril de 2017). En palabras del Alto Tribunal, "la libertad de definir la propia identidad sexual es uno de los elementos esenciales más básicos y que el derecho de las personas transgénero a su desarrollo personal y a la seguridad física y moral está garantizada en el art. 8” (STC 99/2019, de 18 de julio).

El Tribunal Constitucional se pronuncia sobre el libre desarrollo de la personalidad del artículo $10.1 \mathrm{CE}$ con objeto de la cuestión de inconstitucionalidad suscitada sobre el artículo 1.1 de la Ley 3/2007, de 15 de marzo, reguladora de la rectificación registral de la mención relativa al sexo de las personas (en adelante, Ley 3/2007), en la STC 99/2019, de 18 de julio. A tal efecto, señala que se permite a la persona tomar decisiones sobre su identidad que despliegan efectos jurídicos, entendiendo esta última como una cualidad esencial del individuo. Adicionalmente, el Alto Tribunal define la configuración de la identidad como una "decisión vital, en el sentido que coloca al sujeto en posición de desenvolver su propia personalidad”. Este criterio del Tribunal Constitucional, que liga la autodeterminación de la identidad con el derecho al libre desarrollo de la personalidad, es el esgrimido por el legislador en la exposición de motivos de la Ley 3/2007, cuya finalidad es "garantizar el libre desarrollo de la personalidad y la dignidad de las personas cuya identidad de género no se corresponde con el sexo con el que inicialmente fueron inscritas".

Por su parte, el Tribunal Supremo, a partir de la STS 929/2007, de 17 de septiembre, configura el libre desarrollo de la personalidad como fundamento del derecho a sostener la identidad sexual como expresión de la personalidad en los supuestos de disforia de género. Esta línea jurisprudencial se afianza en sentencias ulteriores, entre las que se destacan la STS 158/2008, de 28 de febrero, 182/2008, de 6 de marzo, 183/2008, de 6 de marzo, 731/2008, de 18 de julio y 465/2009, de 22 de junio (ATS de 10 de marzo de 2016).

Por último, en el Derecho Comparado cabe citar al Tribunal Federal Alemán, que basa su análisis del derecho a la identidad sexual en el "derecho general a la propia personalidad" recogido en los artículos 1 y 2 GG (1 BvR 938/81, de 16 de marzo de 1982; 1 BvL 38/92, de 26 de enero de 1993; 1 BvL 3/03, de 6 de diciembre de 2005; 1 BvL 1/04, de 18 de julio de 2006; $1 \mathrm{BvL}$ 10/05, de 27 de mayo de 2008; $1 \mathrm{BvR} 3295 / 07$, de 11 de enero de 2011 y $1 \mathrm{BvR}$ 2019/16, de 10 de octubre de 2017). 


\subsection{Autodeterminación y Convención de los Derechos del Niño}

Para finalizar el tratamiento del principio de autodeterminación en este estudio y establecer la conexión pertinente con el derecho a la educación, se ha de analizar la problemática de la autodeterminación en materia de identidad de género y orientación sexual de los menores de edad.

El artículo 8 de la Convención sobre los Derechos del Niño, de 20 de noviembre de 1989 (RCL 1990, 2712), que adquiere importancia constitucional ex artículo 10.2 CE, proclama el respeto al "derecho del niño a preservar su identidad". No obstante, únicamente se incluye en la literalidad del precepto "la nacionalidad, el nombre y las relaciones familiares" bajo la rúbrica de identidad.

Es especialmente relevante el pronunciamiento del Tribunal Constitucional sobre la rectificación de la mención del sexo por disforia de género de la persona menor de edad, STC 99/2019, de 18 de julio. El Tribunal sostiene que el artículo 1 de la Ley 3/2007 es restrictivo sobre los efectos que se despliegan del precepto del libre desarrollo de la personalidad ex artículo 10.1 CE, en tanto en cuanto supedita la decisión autónoma sobre una cualidad esencial de la identidad, el nombre y el sexo, a la mayoría de edad.

La revisión de la doctrina constitucional permite establecer que los menores de edad son titulares de los derechos fundamentales. Esto se predica sobre los derechos de prestación, como es el derecho a la tutela judicial efectiva, STC 183/2008, de 22 de diciembre, F.J.5, y sobre los derechos de libertad, cuya conexión con el principio de autodeterminación y el libre desarrollo de la personalidad los hace más pertinentes. A tal efecto, cabe citar la STC 141/2000, de 29 de mayo, F.J. 5, que señala que "desde la perspectiva del art. 16 CE los menores de edad son titulares plenos de sus derechos fundamentales, en este caso, de sus derechos a la libertad de creencias y a su integridad moral", añadiendo que la incidencia de la patria potestad sobre el disfrute del menor de los derechos fundamentales "se modulará en función de la madurez del niño". Por otra parte, la STC 154/2002, de 18 de julio, en su F.J.9, extiende la autodeterminación sobre decisiones vitales a los menores de edad, como es el rechazo de una transfusión de sangre con motivo de creencias, sin perjuicio de la peligrosidad vital que conlleva. Esta atribución del Tribunal Constitucional se basa en el derecho fundamental a la libertad ideológica, religiosa y de culto, consagrada en el artículo 16.1 CE. Por último, nada impide que este espacio de libre decisión sobre las creencias, del que goza el menor, se proyecte también sobre la "configuración de las opciones fundamentales de vida, entre las que se cuenta la definición de la propia identidad”. Esta proyección se basa en el derecho a la autodeterminación del sujeto titular de derechos fundamentales en los ámbitos protegidos por el Derecho, como hemos visto anteriormente.

\subsection{Conclusiones preliminares}

En este epígrafe en primer lugar se ha analizado el principio de autodeterminación, entendido como la materialización práctica de la dignidad de la persona, que conlleva una pretensión de respeto por parte de los demás. Añadido a eso, se ha aportado unas nociones jurídico-filosóficas de la concepción moderna de la autodeterminación, destacando las definiciones aportadas por Dworkin, como aquella capacidad de las personas para reflexionar críticamente sobre sus preferencias, anhelos y necesidades primarias, y la capacidad de aceptar o cambiar estas según 
preferencias o valores ulteriores. Estas nociones derivaban, por un lado, en el constitucionalismo de la diversidad de Tully, y, a gran escala, en la autodeterminación política estatal.

En segundo lugar, tras el desarrollo de las nociones básicas de identidad de género y orientación sexual a través de los Principios de Yogyakarta, se ha revisado la jurisprudencia del TEDH, el Tribunal Constitucional, y el Tribunal Supremo en materia de autodeterminación de género y orientación sexual, que permite establecer las siguientes conclusiones.

1. El derecho al libre desarrollo de la personalidad del artículo 10.1. CE, y el derecho a la vida privada estipulado por el artículo $8 \mathrm{CEDH}$, en virtud del artículo $10.2 \mathrm{CE}$, permiten el establecimiento del derecho a la autodeterminación en materia de identidad de género y orientación sexual.

2. El derecho a la autodeterminación de las personas en materia de identidad de género implica la obligación constitucional del Estado de facilitar el cambio de la mención del sexo y el nombre a las personas con disforia de género, como factor esencial de la identidad con eficacia jurídica.

3. El derecho a la dignidad de la persona y el libre desarrollo de la personalidad del artículo 10.1 en relación con el artículo 14 que prohíbe la discriminación por cualquier condición o circunstancia personal o social, implica la obligación de los poderes públicos de proteger la intimidad y dignidad de las personas homosexuales, bisexuales y transexuales. Es decir, evitando su sometimiento a situaciones humillantes, que afloran cuando se ven forzados a manifestar su condición de persona no heterosexual y/o transexual en el ámbito escolar, laboral o frente a las autoridades públicas.

Por último, para conectar con el derecho a la educación, establecimos la titularidad de los menores del afirmado derecho a la autodeterminación. En este sentido, hemos visto como la interpretación del artículo 8 de la Convención de los Derechos del Niño en virtud del artículo 10.2 CE, junto con el arraigo de los Derechos Fundamentales de la Sección 1. a del Capítulo II del Título I y la jurisprudencia del Tribunal Constitucional, permite establecer que el derecho de la identidad del menor se extiende a la autodeterminación en materia de identidad de género y orientación sexual. No obstante, este derecho se verá modulado por la suficiencia de la madurez del menor y la estabilidad de su situación de transexualidad cuando su ejercicio determine efectos jurídicos como el cambio en la mención registral del sexo (STC 99/2019, de 18 de julio, F.J.9).

En definitiva, el derecho a la autodeterminación, extendido a la identidad de género y orientación sexual, se establece en base a los artículos 10.1 CE y $8 \mathrm{CEDH}$, y su titularidad se extiende a los menores de edad. Por último, los poderes públicos, ex artículo $14 \mathrm{CE}$, deberán proteger la dignidad y la intimidad de los menores homosexuales, bisexuales y transexuales de la discriminación que aflora con motivo de su condición en el ámbito escolar.

\section{El derecho a la educación y su finalidad}

En este epígrafe se estudiará la finalidad de la educación en relación con el derecho a la autodeterminación en materia de identidad de género y diversidad sexual. Para ello, en primer lugar, se analizará el artículo 27 de la Constitución española (en adelante, CE). Secundariamente, 
se estudiará la conjunción del artículo 27.2 CE con el artículo 10 CE y el principio de autodeterminación de la personalidad, para desarrollar el proceso de construcción de la identidad a través de la educación. Finalmente, se establecerán las claves de la convivencia democrática actual y el respeto a los derechos fundamentales en la actividad educativa, en aras de analizar el cumplimiento de la finalidad del artículo 27.2 CE.

\subsection{Marco constitucional del derecho a la educación}

Para el análisis del contenido y los fines del derecho a la educación, recogido en el artículo $27 \mathrm{CE}$, es preciso aportar una breve contextualización histórica sobre su desarrollo constitucional.

La Constitución de 1978 es la primera en la historia de nuestro constitucionalismo que proclama de forma consensual el derecho a la educación y de la libertad de enseñanza, a través de su artículo 27. Las Constituciones anteriores ceñían su contenido en la materia al reconocimiento del derecho de creación instituciones educativas y solo la Constitución de 1931 estipulaba la obligatoriedad y gratuidad de la enseñanza primaria en su artículo 48 (Torres Muro, 2012).

El artículo 27 es fruto de dos posturas o inspiraciones ideológicas, una de marcado carácter liberal, en contraposición con una posición "de izquierda", que origina su carácter ambivalente. Esta ambivalencia se observa en el reconocimiento de la vertiente prestacional del derecho a la educación en comparación con el derecho a la libertad de enseñanza, característico de una democracia liberal. En palaras de Canosa Usera, este artículo refleja "el trabajoso consenso constitucional en materia educativa" que deriva en su carácter prolijo y ambivalente (Nogueira Soriano, 1988). No obstante, será este carácter ambivalente y la consecuente amplitud de la habilitación a las Cortes Generales para el desarrollo legislativo del precepto lo que trasladará la tensión entre los dos modelos a las normas reguladoras. Así se obtienen, la Ley Orgánica 5/1980, de 19 de julio, del Estatuto de los Centros docentes (LOECE), y la Ley Orgánica 8/1985, de 3 de julio, reguladora del derecho a la educación (LODE), sobre las que se pronuncia el Tribunal Constitucional reconociendo la libertad del legislador para la fijación de un modelo concreto y estableciendo los límites de esta última (SSTC 5/1981 y 77/1985). Siguiendo al último modelo, se encuentra la Ley Orgánica 1/1990, de 3 de octubre, de Ordenación General del sistema Educativo (LOGSE), modificada por la Ley Orgánica 10/2002, de 23 de diciembre, de Calidad de la Educación (LOCE), a su vez derogada por la Ley Orgánica 2/2006, de 3 de mayo, de Educación (LOE). Esta última fue sustituida por la Ley Orgánica 8/2013, de 9 de diciembre, para la mejora de la calidad educativa (LOMCE), vigente hasta el 19 de enero de 2021, cuando entró en vigor la Ley Orgánica 3/2020, de 29 de diciembre, por la que se modifica la Ley Orgánica 2/2006, de 3 de mayo, de Educación (LOMLOE).

En virtud del artículo 10.2 CE, se debe integrar el significado de nuestro precepto constitucional con la ayuda de los tratados y acuerdos internacionales ratificados por España en materia educativa. Las referencias internacionales destacadas son el artículo 26.3 de la Declaración Universal de Derechos Humanos, de 10 de noviembre de 1948; el artículo 13.3 del Pacto Internacional de Derechos Económicos, Sociales y Culturales, de 19 de noviembre de 1966; el artículo 18.4 del Pacto Internacional de Derechos Civiles y Políticos, de 19 de noviembre de 1966; y el artículo 2 del Protocolo Adicional 1.o, de 20 de marzo de 1952, al Convenio Europeo de Derechos Humanos, de 4 de noviembre de 1950. No obstante, en la comparativa con el artículo 27, este provee mayores coberturas que las normas internacionales referidas, sin perjuicio de las aportaciones de la jurisprudencia del TEDH. 
En suma, el artículo 27.1 CE estipula dos derechos principales: el derecho a la educación y la libertad de enseñanza. Esta doble afirmación implica la garantía del acceso a la educación y la protección del pluralismo educativo en su mayor grado posible, al margen de la escuela pública.

\subsection{Finalidad del derecho a la educación}

El objeto del derecho a la educación y su finalidad quedan recogidos en el artículo 27.2 CE: "La educación tendrá por objeto el pleno desarrollo de la personalidad humana en el respeto a los principios democráticos de convivencia y a los derechos y libertades fundamentales". En este se aprecian dos partes diferenciadas: "el pleno desarrollo de la personalidad humana", que constituye la dimensión subjetiva del objeto del derecho a la educación, y "el respeto a los principios democráticos de convivencia y a los derechos y libertades fundamentales", que conforma la dimensión objetiva y el mínimo acervo común de valores que comparte la sociedad.

La dimensión subjetiva de la finalidad del derecho a la educación, "el pleno desarrollo de la personalidad humana" presenta una innegable relación con el derecho al "libre desarrollo de la personalidad" que recoge el artículo $10 \mathrm{CE}$, dada la configuración como piedra angular y base del sistema de derechos fundamentales de la Sección 2. a del Título I CE. De la conjunción de ambos preceptos se infiere que la educación constituye un vehículo que garantiza que el desarrollo de la personalidad sea pleno y que se realice en libertad. La evidencia de la conexión se deriva de la literalidad de los preceptos y su equivalencia, sin perjuicio de la inexactitud de su identidad.

En la esfera individual, la educación constituye un vehículo para la construcción de la personalidad del individuo y el pleno desarrollo de sus capacidades. Este proceso se realiza a través de la provisión de herramientas para la comprensión y el discernimiento de la realidad que permiten la configuración del alumno en las dimensiones cognoscitiva, afectiva y axiológica. El desenvolvimiento del alumno en estas áreas conlleva la evolución de sus capacidades afectivas, el reconocimiento de la diversidad sexual, el respeto a la igualdad efectiva entre mujeres y hombres, y el análisis crítico de las desigualdades (Exposición de motivos, Ley Orgánica 3/2020, de 29 de diciembre, por la que se modifica la Ley Orgánica 2/2006, de 3 de mayo, de Educación, en adelante, LOMLOE). Por su parte, la Ley Orgánica 8/2013, de 9 de diciembre, para la mejora de la calidad educativa (en adelante, LOMCE) que modifica la LOE, desarrolla que la educación posibilita el desarrollo personal y la integración en la sociedad, ya que determina los objetivos y las ambiciones en materia profesional y personal. Configura así la educación como la clave de la transformación de las personas, señalando que su aprendizaje no puede limitarse a habilidades cognitivas, sino que debe extenderse a competencias trasversales, como la gestión de la diversidad y la confianza individual. Finalmente, califica la educación como determinante, dada su proyección a lo largo de toda la vida de la persona.

Como conclusión preliminar, cabe destacar que los grupos políticos de signo contrario que posibilitaron la aprobación de la LOE y la LOMLOE, y la LOMCE, respectivamente, presentes en el Congreso de los Diputados, coinciden en que la educación constituye un factor clave para la construcción plena de la personalidad en libertad. Entendiendo ambos que el desarrollo de la identidad que tiene lugar a través de la educación no se limita a las habilidades cognitivas, y que su impacto se proyecta a largo plazo. 
En la esfera colectiva, para la sociedad, continuando con el artículo 27.2 CE, este determina que la educación tendrá por finalidad el desarrollo de la personalidad de los alumnos, "en el respeto a los principios democráticos de convivencia y a los derechos y libertades fundamentales”.

Esto se desarrolla en el preámbulo de la LOMLOE, que señala la importancia de la transmisión de un mínimo acervo común de valores que sustentan la convivencia democrática, entre los que destaca la solidaridad y la eliminación de la discriminación. La transmisión de los valores y principios se realiza a través de dos agentes fundamentales: la familia en el ámbito doméstico y el Estado en el ámbito público, a través de la educación. La interacción de este doble eje la veremos posteriormente en la tensión entre los apartados segundo y tercero y sexto del artículo 27 CE. No obstante, es lógico pensar que el Estado, a través de la educación, es el único agente que puede llegar a todos los individuos en todas las etapas de su formación y, por lo tanto, es el encargado de salvaguardar la transmisión del mínimo acervo común de valores para garantizar la convivencia democrática (STC 133/2010, de 2 de diciembre, F.J.5). Esto es coherente con los apartados quinto y octavo del artículo $27 \mathrm{CE}$, que ordenan a los poderes públicos la garantía del derecho a la educación a través de la programación general de la enseñanza y la inspección del sistema educativo, demostrando el vínculo evidente entre educación y democracia.

Continuando con los principios democráticos de convivencia, la LOMLOE, en su artículo primero, apartado b), introduce la equidad como principio del sistema educativo español, matizando su consecución a través de la inclusión educativa. Por otra parte, en su apartado c), se inspira en "la transmisión y puesta en práctica de valores que favorezcan la libertad personal, [...] la tolerancia, la igualdad, el respeto y la justicia, así como que ayuden a superar cualquier tipo de discriminación". Cabe recalcar que estos principios no solo son suscritos por el grupo político que posibilitó la aprobación de esta ley, sino que se mantienen en la ley de signo político contrario, la enunciada LOMCE.

Con objeto de delimitar el alcance del artículo 27.2 CE, se pronuncia el Tribunal Constitucional en la STC 133/2010, de 2 de diciembre, F.J.8, y establece que la transmisión de conocimientos a los alumnos no es la única finalidad que persiguen los poderes públicos en la configuración del sistema educativo, sino que se ha de orientar a "la garantía del libre desarrollo de la personalidad individual" y "la formación de ciudadanos respetuosos con los principios democráticos de convivencia y con los derechos y libertades fundamentales”. En definitiva, concluye que dichas finalidades se satisfacen de forma eficaz a través del establecimiento de un modelo de enseñanza en que el contacto con la sociedad plural constituya una experiencia cotidiana. En este sentido cabe añadir el reconocimiento por el Tribunal Europeo de Derechos Humanos de que la consecución de estos objetivos no puede ser satisfecha al mismo nivel por la educación en el domicilio, sin perjuicio de que la adquisición de conocimientos por parte de los niños sea similar a los provistos por la educación primaria escolar (Caso Konrad c. Alemania, Decisión de admisibilidad de 11 de septiembre de 2006, núm. 35504/2003).

El Tribunal Supremo, y concretamente, la Sección 1. a de la Sala de lo Contencioso-Administrativo, matiza la finalidad de la educación a través de su pronunciamiento del 11 de febrero de 2009. En su F.J.6. el Tribunal Supremo configura, en primer lugar, el significado del pluralismo como componente esencial de "los principios democráticos de convivencia", y recuerda que se proclama a nivel formal como valor superior del ordenamiento jurídico en el artículo 1.1 CE. El eje del pluralismo está constituido por la diversidad de nociones y juicios que plantean los ciudadanos sobre la vida individual y grupal, cuando ejercitan su libertad en 
la configuración de esta. La diversidad y el objetivo de la convivencia entre todos los agentes individuales y colectivos dentro de un mismo espacio llevan a la necesidad de constituir unas bases jurídicas e institucionales que permitan la expresión y el respeto de la diversidad de concepciones de vida. La educación se convierte en un instrumento indispensable para la transmisión a los alumnos de la realidad de la diversidad, la valoración de su trascendencia y la instrucción en su respeto. La transmisión del pluralismo implica "informar, que no adoctrinar" sobre las nociones culturales, morales o ideológicas que existen en cada periodo temporal en la sociedad y exceden el mínimo acervo común de valores. En palabras del Tribunal y "en aras de la paz social, transmitir a los alumnos la necesidad de respetar las concepciones distintas a las suyas pese a no compartirlas”.

En cuanto al respeto de los derechos y libertades fundamentales, el Tribunal explica que establecen el espacio de libertad para hacer de la dignidad de la persona, proclamada en el artículo $10 \mathrm{CE}$, "una realidad viva y no una mera declaración formal". En consecuencia, la actividad educativa no puede estar al margen de la transmisión de los valores morales que son "el corolario esencial" de los derechos fundamentales, positivados en normas jurídicas vinculantes, como la Sección 2. a del Capítulo I del Título II CE. En este sentido, corresponde también a la actividad educativa del Estado "fomentar sentimientos y actitudes que favorezcan su vivencia práctica”.

En suma, la intervención del Estado en materia educativa se orienta a la transmisión del conocimiento básico del funcionamiento de las instituciones del Estado y los valores necesarios para la convivencia democrática, tanto en la educación pública como en la privada (de Montalvo Jääskeläinen, 2018).

Esta intervención del Estado tiene lugar a través de la garantía del derecho de todos a la educación, "mediante una programación general de la enseñanza, con participación efectiva de todos los sectores afectados” (artículo 27.5 CE), y la prestación de la enseñanza básica de forma gratuita (artículo 27.4 CE). La consideración de la dimensión prestacional del derecho a la educación se deriva del artículo 27.4 CE, tal y como interpreta el Alto Tribunal en su STC 86/1985, de 10 de julio. Por último, "los poderes públicos inspeccionarán y homologarán el sistema educativo para garantizar el cumplimiento de las leyes” (artículo 27.8 CE).

No obstante, el Estado, en su actuación, está limitado por la proscripción de adoctrinamiento o neutralidad ideológica, que se presumirá cuando la actividad educativa se oriente a promover la adhesión a los valores morales que subyacen a los derechos fundamentales. En cambio, si se trata de otros valores, su exposición deberá ser estrictamente objetiva y con el propósito de informar sobre el pluralismo de la sociedad referente a cuestiones que son objeto de polémica.

Por otra parte, y como veremos posteriormente, los derechos que recogen los artículos 16.1 y 27.3 CE constituyen un límite a la actividad educativa del Estado. En este sentido, "los planteamientos ideológicos, religiosos y morales individuales en los que existan diferencias y debates sociales", la actividad educativa del Estado se debe limitar a su exposición y transmisión con neutralidad en aras del respeto del espacio de libertad (STS 342/2009, de 11 de febrero, F.J.6).

\subsection{Construcción de la identidad a través de la educación}

Sin perjuicio de que este artículo tiene una vocación de análisis del derecho constitucional, se considera fundamental el tratamiento de los mecanismos sociológicos a través de los cuales se materializa el pleno desarrollo de la personalidad que consagra el artículo $27 \mathrm{CE}$. Por ello, en 
este subepígrafe, estableceré tres herramientas indispensables para la construcción de la identidad en el contexto escolar: el currículo oficial, la pedagogía y el plano informal del alumnado (Kehily, 1999).

La construcción de la identidad se realiza a través de un aprendizaje social, que se lleva a cabo en el ámbito doméstico primordialmente y de forma secundaria en los centros escolares, así como en otros escenarios menos predominantes. El sistema educativo no constituye el único agente socializador, pero dada su universalidad y obligatoriedad ostenta un papel destacado. El centro escolar es el contexto donde se desarrollan las primeras relaciones sociales fuera de la familia, se interactúa con figuras de autoridad ajenas, se aprenden contenidos y normas sociales, y se construye la autoestima y la concepción de uno mismo. Más adelante, en la adolescencia se configuran la identidad y la orientación sexuales, así como los prejuicios asociados (Cerezo Ramírez, 2015).

\subsubsection{El contexto escolar y el currículo oficial}

Los centros escolares están embebidos en un contexto sociocultural específico, conformado por una serie de valores, principios y comportamientos que describen una serie de expectativas sobre el desarrollo del alumnado. En este sentido, la sociedad occidental, de la que forma parte la sociedad española, define unas estructuras de género que distinguen entre comportamientos masculinos y femeninos, patrones que se prolongan al sistema educativo. De la misma manera, "las relaciones específicas de poder que existen en cada sociedad tienen prolongación en el sistema educativo" (Torres, 2005). Por otra parte, Herrero Brasas constata que la actividad educativa constituye la plataforma básica del orden social y la convivencia democrática.

Como se ha visto en el epígrafe anterior, una de las materias sobre las que se construye la personalidad es la identidad de género. En este sentido, se establecen cuatro componentes fundamentales que articulan el sistema de género: las relaciones de poder, el empleo de autoridad; la división del trabajo, la diferenciación de actividades realizadas por hombres y mujeres; los patrones de emoción, los comportamientos sobre los sentimientos; y el simbolismo, como, por ejemplo, códigos lingüísticos y uniformes (Connell, 2006). Todos estos factores y su conjunción determinan la configuración de la identidad y la creación de un sistema de valores, creencias y actitudes. Añadido a esto se encuentra el currículo oficial, cuyos contenidos muestran una imagen determinada sociocultural del género y la sexualidad. En este sentido, se demuestra que existe un sesgo masculino en los libros de texto en tanto en cuanto las aportaciones al conocimiento de carácter femenino no se incorporan al currículo, a lo que se añade la presencia mayoritaria de personajes masculinos que realizan los papeles sociales e históricos más importantes (Peña Calvo \& Rodríguez Menéndez, 2002). De esta forma, en los centros escolares "no sólo se enseña el conocimiento legítimo sino también el comportamiento esperado" (Lomas, 2008). En esta misma línea, Kehily afirma que los aprendizajes sociales tienen una base heterosexual. Esta concepción de la normalidad y la dominancia de la heterosexualidad promoverá el estigma sobre las orientaciones sexuales minoritarias.

\subsubsection{El cuerpo docente y el ejercicio pedagógico}

Las estrategias educativas llevadas a cabo por el personal docente serán otra herramienta para la configuración de la identidad de los alumnos, puesto que pueden sancionar o validar conductas desarrolladas por estos últimos. A tal efecto, se dan tratamientos diferenciados según 
el género y patrones de interacción entre el profesorado y el alumnado que promueven los estereotipos de género. Un ejemplo muy intuitivo de este fenómeno es la relegación de niñas en actividades deportivas como el fútbol y la involucración activa incentivada comparativa de los niños. Este tratamiento diferencial se establece también a través del empleo de un lenguaje distinto, dependiente del género, por parte del personal docente para dirigirse al alumnado (Peña Calvo \& Rodríguez Menéndez, 2002). En definitiva, este tipo de patrones son interpretados por los estudiantes y refuerzan la configuración de su identidad de género.

\subsubsection{El plano informal del alumnado}

Los alumnos aprenden sobre sexualidad y género fundamentalmente al margen del currículo formal, es decir, en el plano informal de la actividad educativa (Torres, 2005). De esta manera, el conocimiento y los valores del alumnado en la materia interactúan con la cultura del centro escolar y determinan el aprendizaje de género. En definitiva, el actor principal en el aprendizaje en materia de sexualidad es la educación informal, los grupos de amigos y el contexto social escolar.

\subsubsection{La identidad homosexual}

La adolescencia en el contexto de la actividad educativa implica la toma de conciencia frente al cambio físico y requiere el posicionamiento de la persona en determinados asuntos configuradores de su personalidad, como es la orientación sexual (Soriano Rubio, 2004). Es entonces cuando comienza la concepción de la persona como un ser sexual para consigo mismo y el resto del mundo. Llegados a este punto, existirán toda una serie de expectativas heterosexuales vinculadas al sexo biológico de cada persona, lo cual lleva a la frustración a adolescentes no heterosexuales, que no cumplen con dichas expectativas (De La Mora \& Terradillos, 2007). Este fallo en la coincidencia con la conducta esperada los conduce a experimentar sentimientos sistémicos de frustración que repercutirán en el desarrollo de su personalidad (Gómez \& Platero, 2007).

En suma, y cerrando el subepígrafe de carácter sociológico, vemos cómo tanto el currículo escolar como el ejercicio de la docencia y el plano informal de los centros educativos son factores determinantes en el proceso de construcción de la personalidad y la identidad de género. Actualmente esos factores configuran un sistema que ensalza la heterosexualidad como la única orientación sexual válida y perpetúa un sistema de género que divide los comportamientos entre masculinos y femeninos, reduciendo así las posibilidades de actuación del alumnado según su género. Esto cobra especial relevancia en edades como la adolescencia, donde la autodeterminación del alumnado se extiende a su orientación sexual y la falta de validación de orientaciones minoritarias conlleva a la frustración y la falta de autoestima de las minorías. En este sentido, cabe recordar el mandato resultante de la interacción de los artículos 10.1 y 27.2 CE. La finalidad de la educación es el desarrollo pleno y libre de la personalidad humana, por lo que cabe establecer que la legislación de desarrollo del derecho a la educación debería proteger la autodeterminación en materia de identidad de género y diversidad sexual de los patrones discriminatorios preexistentes. Solo de esta manera los individuos podrán desarrollar su personalidad a través de la educación, ejercitando una elección libre ante una serie de concepciones vitales objetivamente expuestas y exentas de valoraciones peyorativas. 


\subsection{Discriminación: homofobia y transfobia en el ámbito educativo}

El análisis de la finalidad del derecho a la educación: el pleno desarrollo de la personalidad, el respeto a los derechos fundamentales y la convivencia democrática lleva a estudiar la vivencia práctica de estos objetivos en el desarrollo de la actividad educativa. De esta manera, si se constata que la realidad dista significativamente de los objetivos fijados por el constituyente, cabría modificar la intervención de los poderes públicos a través de la "programación general de la enseñanza”, así como "la participación efectiva de todos los sectores afectados” que estipula el artículo 27.5 CE.

A continuación, se aportarán las definiciones necesarias para entender la convivencia en las aulas, para posteriormente hacer un esfuerzo descriptivo de la discriminación existente con motivo de identidad de género y orientación sexual.

El término bullying, proveniente del inglés, hace referencia a los patrones de comportamiento entre iguales relacionados con la "intimidación, aislamiento, amenaza, insultos sobre una persona o personas que son señaladas como víctimas” (Avilés Martínez, 2002). El acoso escolar se basa en una relación desigual de poder entre alumnos que se pone de manifiesto en la victimización de una parte. El acoso escolar puede tener lugar a través de acciones físicas o verbales, y no es resultado de una provocación por la parte acosada. Con frecuencia este acoso escolar se prolonga y se repite en el tiempo, derivando en problemas de integración en el contexto escolar, así como en trastornos de ansiedad y depresión en la figura de la víctima (Platero Méndez, 2008).

Este fenómeno discriminatorio lo analizaremos sobre dos colectivos de alumnos: los homosexuales y bisexuales, y los transgénero o transexuales.

En primer lugar, sobre el colectivo no heterosexual cabe aportar una definición de la homofobia, aversión a la homosexualidad que se manifiesta en actitudes hostiles respecto a las personas homosexuales, hombres y mujeres. Dichos patrones de conducta tienen un carácter arbitrario y señalan a las personas homosexuales como anormales e inferiores, entre otras consideraciones (Comisión de educación de COGAM, 2005). En este sentido, el acoso escolar homofóbico hace referencia a los comportamientos intimidatorios ejercidos por los agresores que se justifican en la homofobia y el sexismo y que exponen a los alumnos a la exclusión, las amenazas y los ataques. Las víctimas, jóvenes homosexuales, bisexuales y cualquier persona situada fuera de los estereotipos de género serán desvalorizadas e invalidadas, lo cual repercutirá sobre su autoestima y dificultará su integración en el centro escolar (Platero Méndez, 2008).

No obstante, este análisis no pretende realizar una denuncia del acoso escolar, ni plantear una recomendación psicopedagógica para su tratamiento; sino que se busca resaltar que a la homosexualidad se le da un trato diferente y vejatorio en el plano informal de la actividad educativa, y por lo tanto es motivo de discriminación.

Por un lado, es preciso demostrar la conexión entre el acoso escolar y la homofobia. En este sentido cabe destacar el estudio realizado por la Comisión de Educación de COGAM (Colectivo LGTB de Madrid), titulado Homofobia en el sistema educativo (Generelo \& Pichardo, 2005). Dicho estudio era el resultado de una investigación cuantitativa, fruto de un cuestionario a una muestra de 869 alumnos de los institutos públicos de la Comunidad de Madrid, y un trabajo cualitativo extendido a nivel estatal a través de una serie de entrevistas en profundidad a un grupo de jóvenes LGTB de España (Generelo, Pichardo, \& Galofré, 2006). Los resultados llevan a la conclusión de que: existe un profundo desconocimiento de la diversidad 
sexual y “el 30\% de los varones experimentaban un gran rechazo a la misma”. Además, se demostró que todos los ámbitos de socialización: la familia, el colegio, etc., pueden transformarse en "espacios de exclusión” (Generelo, 2016). Estas publicaciones dieron pie a que Coslada (Madrid) y San Bartolomé de Tirajana (Gran Canaria), municipios con perfiles sociológicos muy diferenciados, solicitasen un estudio sobre la integración sexual en sus escuelas a la Federación Estatal de Lesbianas, Gais, Transexuales y Bisexuales (en adelante, FELTB). Fruto de esto, participaron 4.600 jóvenes entre 12 y 19 años, que permitieron extraer las siguientes conclusiones: "al 32\% de los alumnos de ambas localidades le parecía 'mal' o les producía 'asco' la afectividad de dos hombres en público. El 83\% había presenciado insultos a personas LGTB, y el 37\% palizas. El 3,2\% reconocía haberlas propinado”.

Por otro lado, el Instituto de la Juventud (INJUVE) llevó a cabo una serie de investigaciones, entre las que destacamos "Jóvenes y diversidad sexual" (Observatorio de la Juventud en España, 2011), elaborada a partir de un sondeo realizado por el CIS, que constó de 1411 entrevistas a domicilio, proporcionalmente en toda España. De esta investigación se llegó a la conclusión de que entre un 15 y un $20 \%$ de los encuestados rechaza las expresiones físicas de afecto entre homosexuales en público, porcentaje que también rechazaba la igualdad de derechos de personas LGTB. Además, confirmaba la hipótesis de la violencia homofóbica en adolescentes, ya que el $80 \%$ de la población joven española afirma haber presenciado agresiones verbales a personas no heterosexuales, un $40 \%$ ha sido testigo de situaciones de exclusión y el $20 \%$ de violencia física.

Por último, ese estudio constataba que los jóvenes que habían estado en contacto con la diversidad sexual y de género, bien a través del conocimiento directo de personas LGTB o por haber recibido formación, manifestaban actitudes más benevolentes hacia esta (Generelo, 2016).

Añadido a lo anterior, el acoso escolar homofóbico muestra una serie de particularidades: "la invisibilización de la educación formal en el sistema educativo; el rechazo familiar o la falta de apoyo específico y explícito ante las sexualidades minoritarias; el contagio del estigma, no sólo para lesbianas, gais, transexuales y bisexuales sino para quienes les apoyan; y la normalización de la homofobia, que provoca una interiorización negativa del auto-concepto" (Molinuevo Puras, 2007). Asimismo, el acoso escolar homofóbico a menudo describe patrones difícilmente distinguibles de los actos comunes de vandalismo, y pasan inadvertidos por el personal docente y los tutores correspondientes. Asílo prueban una serie de informes, el 50,6\% de los tutores legales ignoran que sus hijos experimentan acoso escolar y el 67,4\% de los que son conscientes son advertidos por el centro educativo (Byrne, 2012; Defensor del Pueblo, 2007).

Cabe preguntarse, consecuentemente, ¿cuál es la motivación de la discriminación y el acoso escolar homofóbico? El estudio coordinado por José Ignacio Pichardo Galán indica que el desconocimiento de las realidades de las minorías sexuales y la ausencia de referentes positivos favorecen el acoso escolar homofóbico (Molinueva Puras, Martín Martín, \& Pichardo Galán, 2007).

En segundo lugar, hemos de analizar la cuestión de los menores transexuales y la transfobia. A tal efecto la transfobia es la discriminación, el miedo y los comportamientos negativos hacia las personas transgénero o transexuales. Sobre los menores se pronuncia Thomas Hammarberg, antiguo Comisario de Derechos Humanos del Consejo de Europa, en su informe Derechos Humanos e Identidad de Género, de 29 de julio de 2009; donde se afirma que los niños y los jóvenes transexuales se enfrentan frecuentemente, tanto en el ámbito escolar como el familiar, a un ambiente inseguro, es decir, a "acoso escolar e incluso expulsión de la familia”. El 16\% 
de mujeres transexuales y el $41 \%$ de hombres transexuales adolescentes habían experimentado graves ataques verbales por sus familias, llegando a un $20 \%$ de estos últimos a ser desheredados y abandonados por sus familias. En este sentido, la falta de orientación, información, apoyo y tratamiento de los niños y jóvenes transexuales deriva en la exclusión de estas personas, su fracaso escolar y el desarrollo de graves trastornos mentales, que a su vez dan lugar a altas tasas de suicidio.

\subsection{Conclusiones preliminares}

En este segundo epígrafe se ha realizado un análisis del desarrollo constitucional del actual precepto 27 de nuestra Carta Magna, centrándonos en su apartado segundo. A tal efecto, se concluye que el desarrollo del derecho a la educación debe estar orientado a garantizar el libre y pleno desarrollo de la personalidad de los individuos, así como el respeto a los principios democráticos de convivencia y los derechos fundamentales.

Continuando con esa lógica, se estudia el proceso de la construcción de la identidad a través de la educación, analizando los factores que determinaban la personalidad en materia de identidad de género y orientación sexual: el currículo oficial, la docencia y el plano informal del alumnado.

Añadido a eso, se realiza un esfuerzo descriptivo de la vivencia práctica de los principios de convivencia democrática y respeto de los derechos fundamentales en la actividad educativa. A tal efecto se considera prioritario señalar la situación actual del acoso escolar basado en la homofobia y la transfobia. Si bien el acoso escolar es un problema profundo del sistema educativo y supone una falta de garantía institucional por parte de los poderes públicos, lo que nos importa en este artículo es que la motivación del acoso sea la identidad minoritaria de las víctimas en materia de género y orientación sexual. Este acoso, así como la falta de tratamiento del asunto por la educación formal y el currículo oficial impiden la autodeterminación de los individuos y quebrantan el principio de respeto de los derechos fundamentales, entre ellos la dignidad y el libre desarrollo de la personalidad. Actualmente el respeto al pluralismo y la diversidad de nociones sobre la vida, como pueden ser las distintas expresiones de la sexualidad y el género, no son una vivencia práctica en los centros educativos. De esta manera, cabe inferir que los poderes públicos no están ejecutando las finalidades mandadas por el artículo $27.2 \mathrm{CE}$

En consecuencia, cabe concluir con una serie de estrategias que actúan contra la discriminación y que promueven el respeto a los derechos fundamentales, basadas en contrarrestar los factores que dan lugar a la homofobia y la transfobia. Destacamos: la instrucción y la formación sobre sexualidad, género y orientación sexual que elimine los estereotipos negativos; la valoración positiva de la expresión de las distintas orientaciones sexuales a través del establecimiento de referentes; y la difusión de los derechos y las obligaciones de la ciudadanía en materia de identidad de género y orientación sexual.

\section{Libertad de enseñanza}

Como se anticipaba anteriormente, el artículo 27.1 CE consagra dos derechos fundamentales: el derecho a la educación y a la libertad de enseñanza. En contraposición al modelo de izquierdas que configura la vertiente prestacional del derecho, el modelo de la derecha protege el pluralismo educativo en su mayor grado, al margen de la escuela pública. 
Se considera fundamental en este artículo analizar la libertad de enseñanza, como límite a la actividad educativa de los poderes públicos y su interacción con la finalidad de la educación y la rúbrica del artículo 27.2 CE.

La libertad de enseñanza y la escuela libre son fruto de la convergencia de cuatro bloques de derechos. En primer lugar, la libertad de creación de centros docentes dentro del respeto a los principios constitucionales ex artículo 27.6 CE. Secundariamente, la libertad de cátedra consagrada erróneamente por el artículo 20.1.c) CE y reconocida desde la libertad de expresión del docente. En tercer lugar, el derecho de los padres a elegir la formación religiosa y moral para sus hijos que esté de acuerdo con sus convicciones, consagrado en el artículo 27.3 CE. Finalmente, en cuarto y último lugar, la intervención de los profesores, los padres y los alumnos en el control y la gestión de los centros sostenidos por la Administración con fondos públicos estipulada por el artículo 27.7 CE.

\subsection{La libertad de creación de centros docentes}

La libertad de enseñanza entraña la libertad de creación de centros docentes con la finalidad de dirigir posteriormente dichos centros. Estos últimos tendrán un carácter propio y un ideario, es decir, la identificación y expresión de pautas ideológicas que se pretenden inculcar al alumnado. Este derecho es una proyección de los derechos consagrados en los artículos 16.1 y 20.1.a), a la libertad ideológica y religiosa, y la libertad de expresión, respectivamente, y se reconoce a las personas físicas y las personas jurídicas.

La libertad de creación de centros docentes se interpreta y se matiza fundamentalmente a través de tres pronunciamientos del Tribunal Constitucional: la STC 5/1981, de 13 de febrero, la STC 77/1985, de 27 de junio, y la STC 31/2018, de 10 de abril. A través de estos se desgranan el alcance y los límites de la rúbrica del apartado sexto del artículo $27 \mathrm{CE}$.

La libertad de creación de centros docentes abarca la opción de crear instituciones docentes al margen de las enseñanzas regladas, no obstante, la "sistematicidad de la acción educativa" justifica que la creación de centros docentes deba realizarse dentro de "límites más estrechos que los de la pura libertad de expresión” (STC 5/1981). Por su parte, la libertad de expresión encuentra sus límites en el apartado cuarto del artículo $20 \mathrm{CE}$ : el respeto a los derechos fundamentales y la necesidad de protección de juventud y la infancia. Además de estos límites, la libertad de creación de centros docentes se enfrenta al respeto de los principios constitucionales, recogidos en el Título Preliminar de nuestra Carta Magna, y los límites derivados de la finalidad del derecho a la educación consagrada en el artículo 27.2 CE, que como hemos visto anteriormente cumplen una función de inspiración positiva.

Añadido a lo anterior, los centros docentes, en tanto en cuanto forman parte del sistema educativo y han de instruir en enseñanzas regladas, deberán dirigir su actividad no sólo al cumplimiento de las finalidades del artículo 27.2 CE ya analizado, sino que también deberán cumplimentar los requerimientos impuestos por los poderes públicos en cada nivel educativo. Por otro lado, es necesario aclarar que la creación de centros docentes no implica la renuncia del Estado "a su función de prestación de servicios educativos", lo cual se infiere de la interacción de los apartados 5 y 6 del artículo 27 CE. El Estado, encargado de la programación general de la enseñanza, regulará la homologación de títulos académicos y profesionales, así como los planes de estudios y currículos (de Montalvo Jääskeläinen, 2018). Por último, cabe añadir que el Estado ostenta la competencia exclusiva en esta materia ex artículo 149.1.30 CE. 
El derecho a la creación de centros docentes implica el establecimiento de un carácter propio y la imposición de un ideario. En este sentido, es muy importante la matización del ideario que realiza la STC 5/1981, como aquel que no se limita a "los aspectos religiosos y morales de la actividad educativa", sino que se extiende a los "distintos aspectos de su actividad". Por otra parte, se encuentra restringido por el respeto a los derechos fundamentales, los principios constitucionales, el "servicio a la verdad", la enseñanza científicamente solvente y las finalidades del artículo 27.2 CE. En este sentido, la neutralidad es únicamente exigible a los centros públicos, ya que el ideario implica decantarse por unas determinadas convicciones ideológicas que se pretenden inculcar al alumnado.

A tal efecto la STC 77/1985, de 27 de junio, en su F.J.8 suscribe la interpretación establecida por la STC 5/1981 con respecto al concepto de ideario. Dicho concepto ha sido integrado por la LOE, y se materializa por ejemplo en la definición del modelo de educación diferenciada.

El establecimiento del ideario está sometido a una autorización reglada a que la Ley sujeta la apertura y funcionamiento de centros privados. No obstante, esto no significa que pueda admitirse la injerencia de una autorización administrativa, ya que asumiría funciones jurisdiccionales que no le competen y sería incompatible con el derecho fundamental de libertad de creación de centros (STC 77/1985). Ello no obsta a que el ideario o carácter propio, que no podrá ser secreto, "pueda ser conocido por las autoridades del Estado" para que protejan el ejercicio del derecho fundamental y garanticen la adecuación de dicho carácter propio a los principios inspiradores del derecho a la educación del artículo 27.2 CE.

En consecuencia, el derecho a establecer un ideario está sujeto a los límites del derecho a la creación de centros de enseñanza. Ambos derechos de libertad no se ejercitan de forma puntual, sino que se proyectan a lo largo del tiempo sobre la dirección de los centros docentes (STC 176/2015, de 22 de julio, F.J.2). En este sentido, la citada STC 77/1985, en su F.J. 20 precisa que el derecho de dirección supone el "derecho a garantizar el respeto al carácter propio y de asumir en última instancia la responsabilidad de la gestión” a través de la proposición de Estatutos y la contratación del personal administrativo y docente. No obstante, la dirección está limitada por la intervención estatal que resulta del apartado noveno del artículo $27 \mathrm{CE}$ para el caso de aquellos centros de enseñanza financiados total o parcialmente por los poderes públicos, que deberán cumplir "los requisitos que la ley establezca”. Por otra parte, esta dirección quedará limitada por el apartado séptimo del artículo $27 \mathrm{CE}$, que manda la intervención en el control y la gestión de los centros a los profesores y padres de los alumnos.

Finalmente, el derecho al ideario está relacionado con el derecho fundamental consagrado en el artículo 27.3 CE, el derecho de los padres a elegir el tipo de formación religiosa y moral para sus hijos concordante con sus convicciones. Sin perjuicio de que no exista una instrumentalidad necesaria, la libertad de creación de centros docentes amplía considerablemente el elenco de opciones para los padres, y da lugar a un mayor pluralismo educativo.

En suma, el derecho fundamental del artículo 27.6 CE no es un derecho absoluto ya que está sujeto a: los principios constitucionales, la garantía del pleno desarrollo de la personalidad humana, el respeto a los derechos fundamentales, la veracidad y la solvencia científica de los contenidos que transmiten, los apartados 7 y 9 del artículo $27 \mathrm{CE}$, y la libertad de cátedra, que se analiza a continuación. 


\subsection{La libertad de cátedra}

La libertad de cátedra es un derecho fundamental, reconocido por el artículo 20.1.c) CE. No obstante, la rúbrica que lo recoge no define los conceptos pertinentes, sino que asume que su significado es conocido. Además, por ley se podrá regular el ejercicio de dicho derecho, salvaguardando su contenido esencial, ex artículo $53 \mathrm{CE}$. Con respecto a su evolución histórica, conviene apuntar que la doctrina de la libertad de cátedra es de origen alemán, establecida en el artículo 152 de la Constitución Imperial de 1849: “La ciencia y su docencia son libres”. Será posteriormente en la Constitución de Weimar, a través del artículo 142, cuando se precisen su contenido y ejercicio práctico (Gónzález del Valle, 1980).

El Tribunal Constitucional define la libertad de cátedra en su STC 217/1992, de 1 de diciembre, como "una proyección de la libertad ideológica y del derecho a difundir libremente los pensamientos, ideas y opiniones de los docentes en el ejercicio de su función". A tal efecto, se trata de uno de los preceptos cuya interpretación ha sido más polémica y cuya ubicación sistemática es más difícil (Fernández-Miranda Campoamor \& García Sanz, 1997).

Con respecto a la titularidad, se ha interpretado tradicionalmente como una libertad que corresponde a los docentes en la enseñanza superior, o más concretamente de los puestos denominados formalmente como cátedras. De hecho, en la doctrina alemana ostentan la titularidad solo aquellos docentes cuya enseñanza deriva de la labor investigadora. Por otra parte, analizando el precepto a la luz de los debates parlamentarios, concluimos que "el constituyente ha querido atribuir esta libertad a todos los docentes, sea cual fuere el nivel de enseñanza en el que actúan y la relación que media entre su docencia y su propia labor investigadora”. Esto no obsta a que se module el contenido del derecho fundamental según el puesto docente (STC 5/1981).

En consecuencia, la libertad de cátedra, a pesar de estar reconocida en todos los niveles educativos, amplía su contenido a medida que el nivel sea superior y halla su máxima expresión en la enseñanza universitaria. Otro de los condicionantes que matizan el contenido de la libertad de cátedra son los planes de estudio: en los niveles educativos inferiores dichos planes serán más concretos, lo que reduce la libertad del docente (Elvira Perales \& González Escudero, 2011). A sensu contrario, en los niveles superiores los planes de estudio plantearán unas directrices, tras lo cual el personal docente tendrá un mayor grado de configuración (STC 179/1996, de 12 de noviembre). En definitiva, se trata de analizar las funciones de la docencia y realizar la comparativa por variables: la transmisión de conocimientos, la valoración y la crítica, la investigación, la metodología y el sujeto receptor del contenido educativo, entre los niveles inferiores de enseñanza y el nivel universitario (Suárez Malagón, 2011). Esta interpretación es reconocida por el Tribunal Constitucional en su STC 5/1981 (F.J.13), que hace depender la amplitud de la libertad de cada docente "del grado de madurez personal de los destinatarios de la enseñanza y el nivel científico de los conocimientos que a ellos se han de transmitir”. Otro factor clave que modula el contenido de la libertad de cátedra es la naturaleza pública o privada del centro educativo, que analizaremos posteriormente.

La libertad de cátedra consiste fundamentalmente en una libertad frente al Estado o los poderes públicos, cuyo contenido se define desde dos planos, negativo y positivo. En los centros de enseñanza públicos en todos sus niveles, la libertad de cátedra tiene un contenido negativo, ya que impide imponer al docente que su enseñanza tenga una orientación ideológica determinada. Tal y como precisa el Tribunal Constitucional en su STC 5/1981, F.J.9 "libertad de cátedra es, en este sentido, noción incompatible con la existencia de una ciencia o una doctri- 
na oficiales”. Por otra parte, la libertad de cátedra tiene un extenso contenido positivo en la enseñanza superior, que se irá reduciendo gradualmente a medida que nos situamos en niveles inferiores. En esta línea, la libertad de cátedra "ampara la libre programación y el desarrollo igualmente libre de la docencia, si bien respetando los planes y programas mínimos establecidos por quienes tienen competencia para ello” (Salvador Martínez, 2006). Por otro lado, Salguero define el contenido positivo de la libertad de cátedra como "una beligerancia intelectual no dogmática, sustentada en el valor de la tolerancia, en el respeto a la dignidad y libre desarrollo de la personalidad, sujeta a las exigencias de la verdad científica e inmune a una ciencia o doctrina oficial”. No obstante, como indicábamos anteriormente, en los niveles de iniciación de la enseñanza no universitaria los poderes públicos establecen los planes de estudios, así como los medios pedagógicos entre los que puede optar el profesor, ex artículo 27, apartados quinto y octavo, por lo que no puede orientar ideológicamente la transmisión de contenido según sus convicciones.

Otro factor que modula la libertad de cátedra es la naturaleza pública o privada del centro de enseñanza, con el matiz de que los centros privados pueden contar con un carácter propio o ideario. A grandes rasgos cabe señalar que la educación en los centros públicos debe ser ideológicamente neutral y aconfesional, mientras que en los centros privados que tengan un carácter propio, los docentes deberán respetar dicho ideario, por lo que la libertad de cátedra será mayor en el primer caso (STC 47/1985, de 27 de marzo).

El fundamento del imperativo de neutralidad ideológica de los centros docentes públicos se encuentra en la constitución de nuestro sistema jurídico político, basado en el pluralismo, la libertad ideológica y religiosa, y la aconfesionalidad del Estado. Esta neutralidad no obsta a que se organicen enseñanzas de seguimiento libre para garantizar el derecho de los padres a elegir la formación para sus hijos concordante con sus convicciones ex artículo 27.3 CE. De esta manera, la neutralidad ideológica en los centros públicos según la LOECE “impone a los docentes que en ellos desempeñan su función una obligación de renuncia a cualquier forma de adoctrinamiento ideológico, que es la única actitud compatible con el respeto a la libertad de las familias que, por decisión libre o forzada por las circunstancias no han elegido para sus hijos centros docentes con una orientación determinada y explícita” (STC 5/1981, F.J. 9). En definitiva, la libertad de cátedra no implica la libertad de propaganda política, dogmatismo y adoctrinamiento (Fernández-Miranda Campoamor \& Sánchez Navarro, 1997). De forma más reciente se pronuncia el Tribunal Supremo en la STS 342/2009, de 11 de febrero, F.J. 15, que analizaremos en profundidad posteriormente, declarando que ni la Administración educativa, ni los centros docentes y profesores concretos están autorizados para imponer o inculcar de forma directa o indirecta puntos de vista sobre cuestiones morales controvertidas en la sociedad española. En conclusión, la docencia está sujeta al rigor científico y exenta de la imposición dogmática como inferimos de los pronunciamientos analizados y la Disposición Adicional Cuarta de la LOE.

Por último, se debe analizar la libertad de cátedra en el contexto de un centro privado con carácter e ideario propio. La libertad del docente en este sentido está limitada por el nivel educativo y por el ideario del centro. A tal efecto, la intromisión de los poderes públicos en la libertad de cátedra del docente de un centro privado sería una violación de la libertad de enseñanza del titular del centro. Por otro lado, cabe preguntarse sobre la colisión entre la libertad de enseñanza del titular del centro que lo dota de un carácter propio y un ideario, y la libertad de cátedra que la CE concede a los profesores de dichos centros. Esto se resuelve por el Alto Tribunal en su STC 5/1981, F.J.10 que expone que la existencia del ideario, conocida por 
el docente en su incorporación al centro o determinada con posterioridad no le obliga "ni a convertirse en apologista del mismo, ni a transformar su enseñanza en propaganda o adoctrinamiento, ni a subordinar a ese ideario las exigencias que el rigor científico impone a su labor". No obstante, la libertad de enseñanza del titular del centro con carácter propio y la libertad de cátedra deben ser compatibles, por lo que "la libertad del profesor no le faculta por tanto para dirigir ataques abiertos o solapados contra ese ideario, sino sólo para desarrollar su actividad en los términos que juzgue más adecuados y que, con arreglo a un criterio serio y objetivo, no resulten contrarios a aquél”. Por lo tanto, el ideario será más limitante respecto a las cuestiones puramente educativas y formativas, que en lo referente a la transmisión de conocimientos "terreno en el que las propias exigencias de la enseñanza dejan muy estrecho margen a las diferencias de idearios".

En suma, la libertad de cátedra se reconoce a todos los docentes, y estará limitada por la programación general de la enseñanza elaborada por los poderes públicos según el artículo 27.5 CE, además de por el rigor científico. Su contenido se gradúa en función del grado de enseñanza, siendo su amplitud máxima en la educación universitaria. Por último, el carácter del centro determinará su contenido, que será más amplio en la escuela pública, sin perjuicio del principio de neutralidad, y menor en el caso de los centros privados con carácter propio, ya que este último deberá ser respetado por la docencia.

\subsection{El derecho de los padres a elegir la formación religiosa y moral para sus hijos que esté de acuerdo con sus convicciones}

\subsubsection{El artículo 27.3 CE}

Los valores superiores del ordenamiento jurídico español, consagrados en el artículo 1 CE, son, entre otros, la libertad y el pluralismo. Estos valores se proyectan en el derecho a la educación, configurando el derecho de los padres a que sus hijos reciban una educación concorde con sus convicciones morales y religiosas. Esta libertad se garantiza por la vía del artículo 27.6 CE ya analizado y por el artículo 27.3 CE, en virtud del cual "Los poderes públicos garantizan el derecho que asiste a los padres para que sus hijos reciban la formación religiosa y moral que esté de acuerdo con sus propias convicciones” (Suárez Malagón, 2011).

Esta libertad constituye una garantía frente a centros educativos públicos, y se pone de relieve en la organización de las asignaturas de religión y su alternativa. Es razonable pensar que esta libertad no se opone frente a los colegios privados, sin perjuicio de que sean concertados, que exhiban un carácter propio, ya que los padres no están obligados a educar a sus hijos en dichos centros. A sensu contrario, se infiere que los padres que llevan a sus hijos a centros con un ideario explícito se adhieren a él, al menos parcialmente. De otra manera, si los padres eligen un centro de enseñanza público, ejercerán el derecho a que sea educado según sus convicciones durante la escolarización del educando. En consecuencia, "sólo los centros públicos tienen obligación de asegurar el pluralismo interno” (Canosa Usera, 2003).

No obstante, los poderes públicos tienen la obligación de garantizar el derecho a la educación a través de la prestación de la enseñanza básica de forma gratuita y una programación general de dicha enseñanza, vid. artículos 27.4 y 5 CE. Además, los poderes públicos inspeccionarán y homologarán el sistema educativo para garantizar el cumplimiento de las leyes, ex artículo 27.8 CE. 
De esta manera, la enseñanza básica obligatoria y gratuita delimita una restricción a la libertad de los padres y los menores de edad, a través de una serie de sanciones que prevén el incumplimiento de los padres (de Montalvo Jääskeläinen, 2018). Es especialmente relevante la delimitación que establece el Alto Tribunal, a través de la STC 133/2010, sobre el fenómeno de la enseñanza en el domicilio. Cierto sector de la doctrina considera que no existe una proscripción de este modelo educativo, siempre que los padres sometan a los hijos a los exámenes oficiales correspondientes (Díez-Picazo Giménez, 2013). Añadido a eso, de la STC 260/1994, de 3 de octubre, se infería que dicho modelo educativo no estaba excluido. No obstante, a través de la STC 133/2010, el Alto Tribunal cierra el debate señalando que no hay laguna legal en la materia ya que la LOCE ya establecía que la enseñanza básica, "incluye diez años de escolaridad" de forma que "iniciará a los seis años de edad y se extenderá hasta los dieciséis”. En definitiva, no escolarizar a los hijos supone un incumplimiento ex lege del deber de los padres. El derecho que ostentan los padres según el artículo 27.3 CE no posibilita a ningún padre a "negar a sus hijos el derecho y el deber de participar en el sistema oficial de educación" por razones pedagógicas (STC 133/2010, F.J.1). Añadido a esto, soluciones intermedias, como un potencial control público periódico sobre la evolución formativa del alumno en el domicilio y un seguimiento de los contenidos transmitidos, no cumplirían con las exigencias del deber de educación de los padres. La libertad de enseñanza de los padres se extiende consecuentemente a "la facultad de enseñar a los hijos sin perjuicio del cumplimiento de su deber de escolarización, de un parte, y a la facultad de crear un centro docente" (F.J.5). El Alto Tribunal fundamenta su interpretación en que la enseñanza ha de "servir también a la garantía del libre desarrollo de la personalidad individual en el marco de una sociedad democrática y a la formación de ciudadanos respetuosos con los principios democráticos de convivencia y con los derechos y libertades fundamentales”. De esta manera, el Tribunal considera que esta finalidad se realiza más eficazmente mediante "un modelo de enseñanza básica en el que el contacto con la sociedad plural y con los diversos y heterogéneos elementos que la integran, [...] forma parte de la experiencia cotidiana que facilita la escolarización” (F.J.8).

En suma, el derecho a la educación incide sobre la libertad ideológica de los padres y la limita en tanto en cuanto se debe garantizar el bienestar, los derechos y libertades del hijo, entre los que se destaca el libre desarrollo de su personalidad (de Montalvo Jääskeläinen, 2018).

Por último, el derecho del artículo 27.3 CE proyecta y configura el vigente principio de neutralidad, mediante la STC 5/1981, que después plasmó el legislador en el artículo 18.1 LODE, que manda a los centros públicos a desarrollar sus actividades "con sujeción a los principios constitucionales, garantía de neutralidad ideológica y respeto de las opciones religiosas y morales a que hace referencia el artículo 27.3 de la Constitución”. En definitiva, la prohibición de adoctrinamiento ideológico se materializa en una doble limitación: la restricción de la libertad de expresión del personal docente, analizada anteriormente, y la renuncia del Estado a la imposición de una doctrina oficial (Suárez Malagón, 2011).

\subsubsection{El artículo $16.1 \mathrm{CE}$}

Según Vega, todas las potenciales objeciones de carácter educativo, fundamentadas en el contenido del currículo y los modelos pedagógicos tienen un mayor impacto sobre el contenido esencial de la libertad religiosa y de conciencia. En el derecho a la educación, como se ha visto anteriormente, no tiene cabida la instrucción orientada ideológicamente. No obstante, más allá del límite del principio de neutralidad en la actividad educativa del Estado, existe una serie de contenidos y modelos curriculares que pueden transgredir la libertad de conciencia de cier- 
tas minorías. Esta colisión pone de relieve una vez más la tensión entre la vertiente prestacional del derecho a la educación y la vertiente de libertad.

En este sentido, el artículo 16.1 CE reza: "Se garantiza la libertad ideológica, religiosa y de culto de los individuos y las comunidades sin más limitación, en sus manifestaciones, que la necesaria para el mantenimiento del orden público protegido por la ley”. Añadido a esto, en virtud del artículo 10.2 CE se debe integrar el significado de nuestro precepto constitucional con la ayuda de los tratados y acuerdos internacionales ratificados por España en la materia, siendo especialmente relevante el CEDH y la jurisprudencia interpretativa del TEDH. A tal efecto, el artículo 9.1 CEDH estipula que: "Toda persona tiene derecho a la libertad de pensamiento, de conciencia y de religión; este derecho implica la libertad de cambiar de religión o de convicciones, así como la libertad de manifestar su religión o sus convicciones individual o colectivamente, en público o en privado, por medio del culto, la enseñanza, las prácticas y la observancia de los ritos”.

Antes de analizar la valoración jurisprudencial de los órganos jurisdiccionales del Estado español sobre la interacción entre los artículos 27.3 y 16.1 CE, se estudiará la jurisprudencia del TEDH en la materia.

En este sentido, son especialmente relevantes los pronunciamientos: SSTEDH 5095/71, Caso Kjeldsen, Busk Madsen y Pedersen, de 7 de diciembre de 1996; 15472/02, Caso Folguero y Otros c. Noruega, de 29 de junio de 2007; 7511/76, Caso Campbell y Cosans c. el Reino Unido, de 25 de febrero de 1982 y 21787/93, Caso Valsamis c. Grecia, de 18 de diciembre de 1996. De los cuales inferimos los siguientes principios:

En primer lugar, el derecho de los padres a decidir la educación que recibirán sus hijos está conectado y es la materialización de la libertad de pensamiento, conciencia y religión que consagra el artículo $9 \mathrm{CEDH}$. La enseñanza pública habrá de ser neutral en aras de respetar la ideología, las creencias y las convicciones filosóficas de los padres. Secundariamente, el derecho de los padres se materializa mediante la libertad de enseñanza y la libertad de creación de centros docentes. En esta línea, en aras de preservar el pluralismo educativo, los poderes públicos no han de impedir la iniciativa privada, siempre que cumplan los requisitos mínimos que establezca el Estado. Añadido a esto, los poderes públicos no podrán realizar ninguna injerencia sobre la escuela pública bajo el pretexto de la escuela privada (STEDH 15472/02, Caso Folguero y Otros c. Noruega, de 29 de junio de 2007). La neutralidad y el pluralismo de la escuela pública se han de salvaguardar, aunque los padres elijan la educación privada que atienda de forma escrupulosa a sus convicciones religiosas (STEDH 5095/71, Caso Kjeldsen, Busk Madsen y Pedersen, de 7 de diciembre de 1996). En tercer lugar, el derecho de los padres es fundamentalmente de libertad negativa, por lo que no se puede inferir la vertiente prestacional de su contenido. En cuarto lugar, la enseñanza pública en asignaturas cuyo contenido incluya cuestiones morales controvertidas no debe imponer o adoctrinar, sino que debe ser expuesto con objetividad y respeto al pluralismo, y debe estar regido por criterios de solvencia científica. En esta línea, la injerencia en la libertad de expresión del docente está justificada porque garantiza el derecho de los padres. El profesor no puede transmitir los conocimientos desde la concepción de una serie de valores, y tampoco puede educar a sus alumnos en una manera de obrar moralmente. Los poderes públicos deberán garantizar que la información y el conocimiento de los proyectos educativos se transmitan de forma crítica y objetiva, especialmente si inciden en lo religioso e ideológico. "El pluralismo, la diversidad y la tolerancia son valores irrenunciables para la escuela pública” (Barrero Ortega, 2009). En quinto lugar, si en la enseñanza pública se transmiten conocimientos desde la ortodoxia de una confesión 
religiosa, como en los sistemas constitucionales de Reino Unido, Dinamarca, Noruega, Suecia, Finlandia y Grecia, los padres podrán oponerse a que sus hijos asistan a dichas sesiones. El conflicto que tiene lugar como consecuencia de la enseñanza confesional y la libertad religiosa e ideológica de los padres les exime del deber de educación en dicha materia. No obstante, esto no faculta a los padres a oponerse a la integración de una educación religiosa pluralista en el programa escolar, sino únicamente cuando esta sea manifiestamente confesional. En último lugar, las facultades de los padres podrán oponerse tanto al contenido de las asignaturas como también a prácticas o acciones disciplinarias (SSTEDH 7511/76, Caso Campbell y Cosans c. el Reino Unido, de 25 de febrero de 1982 y 21787/93, Caso Valsamis c. Grecia, de 18 de diciembre de 1996).

Finalmente, debemos detenernos en la STEDH 5095/71, Caso Kjeldsen, Busk Madsen y Pedersen, de 7 de diciembre de 1996, dado que versa sobre la oposición de tres matrimonios daneses a la educación sexual integrada en la escuela primaria, fundamentada en el artículo 2 del Protocolo Adicional 1. al CEDH, entre otros. Dicho artículo, análogo al artículo 27. CE, reza: "El Estado, en el ejercicio de las funciones que asuma en el campo de la educación y de la enseñanza, respetará el derecho de los padres a asegurar esta educación y esta enseñanza conforme a sus convicciones religiosas y filosóficas”. En este caso, el Tribunal declara que dicha educación sexual, pese a incluir "consideraciones de orden moral", "revisten un carácter muy general y no entrañan un rebasamiento de los límites de lo que un Estado democrático puede concebir como interés público". En consecuencia, el examen de la legislación danesa en la materia no constituye un adoctrinamiento en tanto en cuanto no exalta un comportamiento sexual determinado. Además, esto no merma el derecho de los padres "de aclarar y aconsejar a sus hijos, de ejercitar con ellos sus naturales funciones de educadores o de orientarles en una dirección, conforme a sus propias convicciones religiosas o filosóficas”. Por último, aduce que, si bien se pueden producir abusos en la aplicación de la legislación danesa por parte del personal docente, los poderes públicos deberán velar por que los derechos de los padres no sean infringidos por el potencial proselitismo de la docencia. En conclusión, la legislación danesa que ordena la educación sexual integrada en la escuela primaria no hiere en sí las convicciones filosóficas y religiosas de los demandantes en la medida prohibida por el artículo 2 del Protocolo citado, ni infringe la libertad religiosa del artículo $9 \mathrm{CEDH}$.

\subsubsection{La asignatura obligatoria de Educación para la ciudadanía}

A continuación, se analizará la obligatoriedad de la asignatura de Educación para la ciudadanía, que ha dado lugar a numerosos pronunciamientos por diversos órganos jurisdiccionales, y cuya finalidad y contenido nos permitirán realizar una analogía con la educación de género y diversidad sexual.

La “educación para la ciudadanía” consiste en un conjunto de asignaturas que la LOE integró en el sistema educativo español. Dichas asignaturas eran obligatorias y evaluables para toda clase de centros educativos: públicos, concertados y privados. Se impartía en dos cursos del tercer ciclo de Primaria (vid. artículo 18.3 LOE), y en uno de los tres primeros cursos de la Educación Secundaria Obligatoria (vid. artículo 24.3 LOE) bajo la rúbrica de "Educación para la ciudadanía y los Derechos Humanos”. Su introducción dio lugar a numerosas confrontaciones en el ámbito educativo, que derivó en su aplicación desigual según el Gobierno de cada comunidad autónoma, así como en los recursos de numerosos padres que pretendían que sus hijos no fueran educados en esa asignatura (Arpal Andreu, 2009). Es por ello que la 
jurisprudencia en la materia es prolija y ambivalente, hasta su unificación por el Tribunal Supremo en la Sentencia 342/2009, de 11 de febrero.

Como precedentes o motivaciones que guiaron la implementación de la asignatura, cabe destacar: la Recomendación (2002) 12 del Comité de Ministros del Consejo de Europa y la Recomendación Conjunta del Parlamento Europeo y del Consejo sobre las competencias clave para el aprendizaje permanente, de 18 de diciembre de 2006. Por otra parte, la LOE fue desarrollada por reales decretos, en cuyos anexos figuran los objetivos, contenidos y criterios de evaluación de las asignaturas mencionadas: el Real Decreto 1513/2006, de 7 de diciembre, por el que se establecen las enseñanzas mínimas de la Educación Primaria y el Real Decreto 1631/2006, de 29 de diciembre, por el que se establecen las enseñanzas mínimas correspondientes a la Educación Secundaria Obligatoria.

A continuación, cabe analizar las resoluciones de los Tribunales de Justicia (en adelante, TSJ) en la materia. Principalmente, los recursos contencioso-administrativos exigían el reconocimiento del derecho a la objeción de conciencia o impugnaban directamente la norma autonómica que desarrollaba la normativa estatal. El fundamento de los recursos se centraba en que la asignatura de Educación para la ciudadanía suponía una imposición moral particular, en relación con la ideología de género, y que por tanto vulneraba los artículos 16.1 y 27.3 CE.

Ante estos recursos, los TSJ de cada comunidad autónoma se pronunciaron de forma no unificada, alternativamente, estimando o desestimando dichos recursos.

Por un lado, se distinguen entre sentencias estimatorias, la SSTSJ de Andalucía 7613/2008, de 30 de abril, y 539/2008, de 4 de marzo. La primera alega la vulneración del principio de neutralidad ideológica por los Reales Decretos que desarrollan la LOE con motivo de la imposición de la ideología de género. La segunda reconoce el derecho a la objeción de conciencia con respecto a no cursar la asignatura objeto de recurso. Añadido a estas, son especialmente relevantes los pronunciamientos del TSJ de la Rioja, vid. SSTSJ 177, 196 y 197/2008, mediante los que se considera que la objeción de conciencia no está limitada al artículo $30.2 \mathrm{CE}$ como "derecho fundamental integrante del derecho fundamental de libertad ideológica", sin perjuicio de que no existe ley que regula la objeción en materia educativa. La Sala del TSJ de la Rioja estableció la inexistencia de una ética pública y considera que la educación para la ciudadanía incluye "un contenido de formación moral” así como una "expresa pretensión de conformar en los alumnos, una conciencia moral concreta, [...] imponiéndoles como normas morales una serie de valores concretos elegidos por el Estado". No obstante, como veremos posteriormente, el Tribunal Supremo refutará estos argumentos a través de su Sentencia del 11 de febrero de 2009.

Por otro lado, se pronunciaron una amplia serie de sentencias desestimatorias, vid. STSJ del País Vasco 835/2008, de 10 de diciembre; STSJ de Madrid 1917/2008, de 6 de octubre; STSJ de Asturias 197 y 198/2008, de 11 de febrero; y STSJ de Navarra 465/2008, de 9 de octubre. Sus fundamentos de derecho para la desestimación de los recursos contencioso-administrativos son confirmados por la STS 342/2009, de 11 de febrero, que analizaremos a continuación.

La doctrina definitiva en esta materia se establece por el Tribunal Supremo en las Sentencias 340, 341 y 342/2009, de 11 de febrero, que resuelven recursos de casación contra las Sentencias de los TSJ antes mencionadas, y cuya fundamentación coincide. Dichos pronunciamientos se extienden sobre cinco cuestiones: el significado del pluralismo en el seno de la sociedad democrática; la relevancia de los derechos fundamentales; el papel que la Constitución le otorga al Estado en materia de educación; el contenido del artículo 16.1 CE dentro del sistema edu- 
cativo; el alcance del contenido del artículo 27.3 CE y el límite que supone para la actividad educativa de los poderes públicos (F.J.6).

1. El significado del pluralismo en el seno de la sociedad democrática.

Como se ha visto anteriormente, la educación es una herramienta esencial para garantizar la vivencia práctica del pluralismo en sociedad, así como para trasmitir a los alumnos la diversidad de nociones sobre la vida y la necesidad de su respeto. En definitiva, el pluralismo implica "informar, que no adoctrinar, sobre las principales concepciones culturales, morales o ideológicas que, más allá de ese espacio ético común, pueden existir en cada momento histórico dentro de la sociedad”.

2. La relevancia de los derechos fundamentales.

Con respecto a los valores, se definen como aquellos que "constituyen el sustrato moral del sistema constitucional y aparecen recogidos en normas jurídicas vinculantes, representadas principalmente por las que reconocen los derechos fundamentales". Por otro lado, cuando la actividad educativa del Estado está referida a estos valores, no solo le compete su transmisión, sino que también está legitimado en el fomento de actitudes que promuevan su vivencia práctica.

3. El papel que la Constitución le otorga al Estado en materia de educación.

La conjunción de los mandatos establecidos en los apartados 5 y 2 del artículo 27 CE, implica que el Estado está obligado a prestar su actividad en materia educativa. Además, esta intervención estará dirigida a la transmisión del conocimiento de las bases institucionales del Estado y la instrucción en los valores necesarios para garantizar la convivencia democrática y el funcionamiento del Estado. Por último, la programación y el contenido estatal vincularán a la enseñanza pública y privada, dada la conexión entre la democracia y la educación.

4. El contenido del artículo 16.1 CE dentro del sistema educativo.

La Constitución únicamente posibilita la objeción de conciencia frente a la exigencia del cumplimiento de un deber público, como se prevé en el artículo 30.2 CE. Al margen de este caso, solo se ha admitido dicho derecho al personal sanitario que ha de intervenir en la práctica del aborto, en sus modalidades despenalizadas. En palabras del Tribunal, "ni las normas internacionales, ni la jurisprudencia del Tribunal Europeo de Derechos Humanos lo han reconocido en el ámbito educativo" (F.J.7).

5. El alcance del contenido del artículo 27.3 CE.

Dada la inexistencia de la objeción de conciencia con alcance general, el Tribunal analiza si se pudiera plantear la objeción de conciencia en la enseńanza en aras de lo estipulado por el artículo 27.3 CE. En este sentido, el Tribunal rechaza la aplicabilidad de la jurisprudencia del TEDH, en concreto la analizada STEDH 15472/02, Caso Folguero y Otros c. Noruega, de 29 de junio de 2007, considerando que, si bien faculta a la objeción de conciencia en materia educativa, lo hace con respecto a la asignatura obligatoria de religión. Esta situación no se da en España ya que las asignaturas de religión en el currículo tienen carácter optativo, por lo que no se genera automáticamente el derecho a la objeción de 
conciencia respecto de materias ajenas a la religión. Por lo tanto, habría que analizar la magnitud del impacto de la asignatura sobre las cuestiones morales. Los recurrentes alegan que el contenido de Educación para la ciudadanía implica el adoctrinamiento en el relativismo, el positivismo y la ideología de género. Frente a esto, el Tribunal argumenta que "no cabe deducir de la configuración que se ha dado a la materia Educación para la ciudadanía las ideas de que no hay otra moral que la que recogen las normas jurídicas, que el ordenamiento jurídico admite cualquier contenido con independencia de su significado ético y que las normas reglamentarias asuman una denominada 'ideología de género', concebida en los términos que parecen deducirse de sus escritos” (F.J.10). Contra el relativismo moral y la tacha de totalitarismo del recurso, el Tribunal recuerda que la Educación a la Ciudadanía pretende instruir en los valores de la Constitución, entre los que se halla el pluralismo. Por otro lado, con respecto a la ideología de género el Tribunal alega que no se indica el contenido del concepto, ni sus efectos perjuiciosos que se le atribuyen a las normas del contenido de la asignatura en cuestión. Por último, no se aprecia el adoctrinamiento ya que la enseñanza en la materia persigue el conocimiento y el respeto de los valores y no así "que los acepten en el fuero interno como única y exclusiva pauta a la que ajustar su conducta ni que renuncien a sus propias convicciones”.

6. El límite que suponen los apartados 4 y 5 para la actividad educativa de los poderes públicos.

"Los apartados segundo y tercero del artículo 27 se limitan mutuamente”, el Estado no puede excederse e invadir el derecho de los padres a elegir una educación para sus hijos acorde con sus valores, pero los padres no pueden extenderse hasta el punto en el que el deber del Estado de garantizar una educación se desvirtúe.

En consideración de todo lo expuesto, se establecen las siguientes conclusiones:

1. La normativa de desarrollo de las asignaturas de Educación para la ciudadanía es conforme a Derecho. La actividad educativa del Estado es obligatoria y se extiende a toda la enseñanza, por la conexión entre la educación y la democracia. En definitiva, cursar la materia referida constituye un deber jurídico.

2. No hay derecho a la objeción de conciencia con alcance general derivado del artículo $16 \mathrm{CE}$.

3. No hay un derecho a la objeción de conciencia circunscrito al ámbito educativo, con base en el artículo 27.3 CE en materias ajenas a la enseñanza obligatoria de la religión. "Los padres no tienen un derecho ilimitado a oponerse a la programación de la enseñanza por el Estado” (Arpal Andreu, 2009).

\subsubsection{La educación de género y diversidad sexual}

Para poder establecer la analogía de la educación de género y diversidad sexual con la "Educación para la Ciudadanía” y establecer su naturaleza considerando el análisis expuesto de los artículos 10 y $27 \mathrm{CE}$ se ha de proponer un modelo educativo en la materia.

Para la proposición del modelo, nos basaremos en las buenas prácticas de otros países y comunidades autónomas (Pichardo Galán, de Stéfano Barbero, Faure, Sáenz, \& Williams Ramos, 
2015). En primer lugar, cabe desarrollar el caso de Bélgica, cuya Comunidad Flamenca trata la sensibilización y el respeto en relación con la identidad de género y diversidad sexual a través de dos asignaturas obligatorias, Educación a la ciudadanía y Educación para la vida relacional, afectiva y sexual (EVRAS). Por otro lado, Argentina, desde 2006, en el contexto de su Programa Nacional de Educación Sexual Integral, y a través del Ministerio de Educación de la Nación, implementa un programa de educación sexual en toda la enseñanza no universitaria. Este programa abarca la diversidad en la sexualidad, además de las distintas configuraciones familiares y el respeto a las distintas nociones de vida. En tercer lugar, tenemos el caso de Quebec (Canadá), donde se estableció la Cátedra de Estudios sobre la homofobia en la Universidad de Quebec en Montreal. Además, tiene lugar cada dos años un congreso contra la homofobia del que forman parte los agentes de la actividad educativa: el Ministerio de Educación, el Ministerio de Enseñanza Superior e Investigación, los equipos directivos de los centros de enseñanza, asociaciones de estudiantes y de padres, y universidades.

Por otro lado, en el panorama nacional tenemos, en primer lugar, a Andalucía, que en desarrollo de la Ley 2/2014, de 8 de julio, integral para la no discriminación por motivos de identidad de género y reconocimiento de los derechos de las personas transexuales de Andalucía, introdujo el Protocolo de actuación sobre identidad de género en el sistema educativo andaluz. Este Protocolo ofrece principios generales de actuación sobre cómo proceder cuando un alumno necesita atención educativa en materia de identidad de género, y establece un procedimiento de comunicación e identificación para prevenir, detectar e intervenir ante el acoso escolar transfóbico. En segundo lugar, Canarias sigue una actuación transversal en materia de identidad de género y diversidad sexual: desarrolla una Acreditación en Igualdad para el profesorado responsable de los centros públicos, que abarca el fomento del respeto y la integración de la diversidad sexual. En esta línea, desde 2013 también procura el proyecto "Diversigualdad" dirigido al segundo ciclo de educación infantil y el primer ciclo de educación primaria, que educa en la diversidad sexual a través de contenidos adaptados a cada nivel. Este programa tiene su análogo para secundaria y bachillerato, denominado "Diversidades en construcción: una cuestión de educación”. Finalmente, también publica unas "Recomendaciones para docentes” para la atención a niños con disforia de género. En tercer lugar, Extremadura, cuyo Parlamento en 2015 aprobó la Ley de igualdad social de lesbianas, gais, bisexuales, transexuales, transgénero e intersexuales y de políticas públicas contra la discriminación por orientación sexual e identidad de género en la comunidad autónoma de Extremadura, que incluye un capítulo de normas en el ámbito educativo; destacan, entre ellas, el uso de contenidos educativos inclusivos respecto a la diversidad sexual, así como la detección y protección de las minorías sexuales en los centros educativos. Por último, está el caso del País Vasco, cuyo servicio de Información y atención para los temas de diversidad sexual y género ha configurado un mecanismo de acción específico, Berdindu Eskola, que desarrolla un servicio de asesoramiento a centros de enseñanzas con problemas de discriminación y acoso escolar homofóbico, así como a centros que quieren integrar la diversidad sexual en el plan curricular. Por otro lado, con respecto a la docencia, el plan de trabajo 2011-13 por la igualdad y la no discriminación por orientación sexual e identidad de género, elaborado por el Gobierno Vasco, incluye: jornadas formativas anuales para los docentes que incorporan la diversidad sexual, la incorporación de una asignatura obligatoria en la materia en la Universidad del País Vasco para los grados de Magisterio, Pedagogía y Formación del Profesorado de Educación Secundaria.

En suma, desde este artículo se propone un modelo educativo integral a través de tres líneas de acción. En primer lugar, la educación del personal docente, a través de jornadas formativas, para que estén sensibilizados y puedan actuar frente al acoso escolar homofóbico y transfó- 
bico. Secundariamente, formación obligatoria en la Escuela Primaria y la Escuela Secundaria cuyo contenido, adaptado respectivamente, exponga las distintas nociones de configuración familiar en España y las diversas formas de expresión de la orientación sexual e identidad de género, en tanto en cuanto desarrollarse libremente en dichos aspectos constituye un derecho fundamental. Por último, el establecimiento de unos principios de procedimiento y un modelo de acción para atender a los menores que solicitan atención educativa con motivo de disforia de género.

\subsection{La intervención de los profesores, los padres y los alumnos en el control y la gestión de los centros sostenidos por la Administración con fondos públicos. El pin parental}

\subsubsection{El artículo 27.7 CE}

Por último, para analizar la libertad de los padres frente al contenido educativo de carácter estatal en base a los apartados 2, 4 y 5 del artículo $27 \mathrm{CE}$, se ha de tratar el apartado 7, que configura el derecho de intervención de los profesores y los padres "en el control y gestión de todos los centros sostenidos por la Administración con fondos públicos, en los términos que la Ley establezca”.

El legislador queda habilitado para desarrollar el precepto con los límites que establecen los artículos 53.1 y 81.1 CE. En consecuencia, el legislador ha desarrollado "una estructura orgánica básica de los centros públicos [...], que precisa en detalle la composición de los principales órganos de gobierno y el contenido esencial de sus atribuciones" (STC 5/1981, de 13 de febrero, F.J.15).

En definitiva, este derecho se materializa a través de la creación de órganos colegiados y la participación a través de estos. Constituye un cauce institucional que tomará las decisiones más relevantes para la comunidad escolar. Ello no obsta a que los titulares del derecho ex artículo 27.7 CE no lo realicen de forma individual con el objetivo de resolver problemas mediante conversaciones entre padres y profesores, o quejas formuladas por los padres dirigidas al centro (STC 5/1981, F.J.18).

\subsubsection{El pin parental}

Por último, cabe tratar el renombrado pin parental, que diseña un sistema de cheque escolar y autorización expresa que permite a los padres elegir la educación de sus hijos, en concreto sobre la asistencia a "cualquier actividad con contenidos de valores éticos, sociales, cívicos morales o sexuales” (VOX, 2019). El pin parental es una propuesta en materia de política educativa introducida por el partido político Vox en su programa electoral para las elecciones autonómicas de 2019.

Sin perjuicio de las refutaciones implícitas que suponen la inexistencia de la objeción de conciencia en materia educativa con base en los artículos 16.1 y 27.3 CE, y las limitaciones del artículo 27.3 CE por el deber de educación de los padres ex artículo 27, apartados 2, 4 y 5, cabe plantear las siguientes observaciones. 
El pin parental se sustenta sobre tres argumentos: en primer lugar, que son los padres los que deciden sobre las cuestiones básicas que afectan a sus hijos y por lo tanto dicho poder no corresponde al Estado. En segundo lugar, que son los padres los competentes para decidir la educación que han de recibir sus hijos en todo lo referente al ámbito axiológico y moral. Y finalmente, que deben quedar fuera de la educación las enseñanzas, teóricas o prácticas sobre cuestiones de ideología de género y diversidad sexual que los padres consideren perjudiciales para los hijos.

Con respecto a las primeras afirmaciones cabe realizar las siguientes refutaciones; por un lado, los niños son sujetos titulares de derechos, entre los que figura "la adquisición de una identidad personal y la gestión de su propia sexualidad”, según las conclusiones establecidas en el epígrafe 2 y la Observación General núm. 4 de la Convención de los Derechos del Niño. Por otro lado, este derecho se realiza a través de la educación, que constituye un vehículo para el libre desarrollo de la personalidad, como hemos visto anteriormente. El Estado tiene el deber de intervenir en esta educación ex artículo 27 apartados 4 y 5 CE a través de la prestación gratuita y la programación de la enseñanza, que instruirá en conocimientos, pero también transmitirá los valores para garantizar el respeto a los derechos fundamentales fomentando su vivencia práctica. En definitiva, los niños no pertenecen a los padres, ni estos últimos tienen una competencia ilimitada sobre la educación de sus hijos, como se extrae de la analizada STC 133/2010. En su lugar, los padres tienen el deber de garantizar el derecho a la educación de sus hijos y por lo tanto tienen la obligación de escolarizarlos. Además, no tienen la facultad de sustraer a sus hijos de las actividades educativas referentes al ámbito moral que fomentan el respeto de los derechos fundamentales, como es la autodeterminación en materia de identidad de género y diversidad sexual, y siendo otros valores, cuando estos se expongan desde una perspectiva plural y objetiva, en virtud de la STS 341/2009 ya analizada. Por último, con respecto a la ideología de género, y a la diversidad sexual, no se define la citada ideología de género ni se prueban los perjuicios que se alegan a las actividades formativas complementarias ofrecidas desde una perspectiva de género, en atención a la Recomendación (2002) 12 del Comité de Ministros del Consejo de Europa. Finalmente, la educación en diversidad sexual no es perjudicial, en tanto en cuanto protege el libre desarrollo de la personalidad en materia de sexualidad y fomenta el respeto a orientaciones sexuales minoritarias, informando sobre su existencia sin la exaltación de ninguna conducta en particular, como hemos visto en los modelos educativos expuestos sobre la materia.

Por todo lo expuesto, solo cabe concluir que el renombrado pin parental no es conforme a derecho.

\subsubsection{Conclusiones preliminares}

Con carácter previo a la exposición de las conclusiones globales de este trabajo, cabe aunar las conclusiones extraídas del análisis del epígrafe cuarto.

En primer lugar, con respecto a la libertad de creación de centros y el establecimiento de un ideario, esta queda sujeta a la enseñanza de contenido científicamente solvente. De esta manera, si la Organización Mundial de la Salud no reconoce ni la homosexualidad ni la disforia de género como una enfermedad, no se puede instruir en tal calificación, ya que no sería científicamente veraz. Además, deberá educar en el respeto a los derechos fundamentales, según el artículo 27.2 CE, y por lo tanto en el respeto al libre desarrollo de la personalidad en materia de género y orientación sexual, analizado en el segundo epígrafe. 
Secundariamente, en relación con la libertad de cátedra, esta quedará limitada por el rigor científico antes mencionado y la programación general de la enseñanza materializada en planes de estudio según los apartados 4 y 5 del artículo 27. De esta manera, si la educación de género y orientación sexual forma parte de dichos planes, los docentes quedarán vinculados por estos contenidos. Por otra parte, la docencia de la escuela pública está sujeta al principio de neutralidad, en contraposición a los profesores de los centros privados que deberán respetar el ideario de dichos centros.

En tercer lugar, sobre el derecho de los padres de elegir la educación para sus hijos en materia religiosa y moral, cabe destacar que tienen el deber de escolarizar a sus hijos en el sistema de enseñanzas regladas. El Tribunal Constitucional lo justifica apoyándose en que la escolarización es el método más eficaz para realizar las finalidades del artículo 27.2 CE. Añadido a esto, el artículo 27.3 CE implica la prohibición de adoctrinamiento por parte del Estado y, consecuentemente, la existencia de una moral o doctrina oficial. En este sentido, el Caso Kjeldsen, Busk Madsen y Pedersen (STEDH 5095/71, de 7 de diciembre de 1996), es especialmente relevante, ya que señala que la educación sexual no tiene un carácter adoctrinador dada su generalidad y la ausencia en su contenido de la exaltación de comportamientos sexuales determinados. Por otro lado, de la STS 341/2009, de 11 de febrero, inferimos que no hay derecho a la objeción de conciencia con alcance general ni circunscrita al ámbito educativo. En cambio, será obligatoria la educación en los valores inspirados por los derechos fundamentales y será lícito el fomento de su vivencia práctica. Finalmente, hemos propuesto un modelo de educación de género y diversidad sexual integral, cuya naturaleza jurídica equiparamos a la analizada asignatura de Educación para la ciudadanía en tanto se limita a una exposición informativa de la existencia de diversas orientaciones sexuales y expresiones de género, fruto del libre desarrollo de la personalidad. En definitiva, no se trata de la exaltación de un comportamiento sexual, sino de la información objetiva para evitar la discriminación de minorías y garantizar que la educación sea un vehículo para el libre desarrollo de la personalidad en esos ámbitos.

Por último, se ha desarrollado la antijuridicidad del renombrado pin parental en aras de todo lo expuesto anteriormente.

En suma, en palabras de Canosa Usera, "ni hay un derecho a recibir ensenáanzas contrarias a las finalidades del artículo 27.2 CE, ni la libertad de impartirlas”.

\section{Conclusiones}

Finalmente, se ha de contestar a la pregunta que ha dado lugar a este trabajo, ¿es la educación de género y diversidad sexual una imposición ideológica o una obligación constitucional?

Para ello, en primer lugar, nos centrábamos en el análisis del artículo 10.1 y la rúbrica del libre desarrollo de la personalidad. La revisión de la jurisprudencia del TEDH, el Tribunal Constitucional y los Tratados internacionales suscritos por España nos llevan a diversas conclusiones. En primer lugar, que la conjunción del derecho al libre desarrollo de la personalidad y el derecho la vida privada, que consagran el artículo $10 \mathrm{CE}$ y el artículo $8 \mathrm{CEDH}$, respectivamente, configura el derecho a la autodeterminación de género y orientación sexual, fundamento de la igualdad de derechos del referido colectivo LGTB. Este derecho, en relación con la dignidad de la persona, piedra angular de los derechos fundamentales y la prohibición de la discriminación del artículo $14 \mathrm{CE}$, implica proteger la intimidad y la dignidad de las personas del colectivo LGTB, evitando situaciones humillantes y de exclusión que surgen en los ámbitos escolar y 
laboral. La titularidad del derecho de autodeterminación en materia de identidad de género y orientación sexual se extiende a los menores de edad, como inferimos del artículo 8 de la Convención de los Derechos del Niño y la jurisprudencia del Tribunal, en la que destacamos la citada STC 99/2019, sin perjuicio de que su contenido se module en función de su madurez.

En segundo lugar, se constataba que la educación es el vehículo que garantiza el pleno y libre desarrollo de la personalidad, en virtud del artículo 27.2 CE, que erige dicha finalidad como objeto de la actividad educativa. Ańadido a esto, el derecho a la educación en su vertiente prestacional es una intervención de los poderes públicos intrínsecamente conectada con la democracia, ya que es el único agente social que puede construir el mínimo acervo común de valores que posibiliten la convivencia. Estos son el pluralismo, la libertad, la justicia, la igualdad y el respeto a los derechos fundamentales. El Estado tiene el deber de transmitirlos y fomentar su vivencia práctica, y no limitarse a la formación en conocimientos, a través de la programación general de la enseñanza según el artículo 27.5 CE. No obstante, la discriminación sistemática por motivos de orientación sexual persiste en la sociedad y en los centros educativos. Esto implica un ataque contra la dignidad de las personas LGTB y supone una falta de respeto de sus derechos fundamentales, lo cual, a su vez, impide y dificulta su libre desarrollo de la personalidad. La construcción de la identidad en materia de sexualidad y género se da mayoritariamente a través del plano informal o currículo oculto de la enseñanza, lo cual implica una pérdida de objetividad y una continuidad del desconocimiento y la desinformación sobre la orientación sexual. Esto constituye un factor que favorece la discriminación homofóbica y transfóbica, potenciándola, incentivando la exclusión. En consecuencia, si la formación en diversidad sexual y de género conlleva un mayor respeto de los derechos fundamentales de esas minorías, los poderes públicos deberían modificar la programación general de la enseñanza en esta línea para materializar las finalidades del derecho a la educación.

En tercer lugar, se ha analizado la libertad de enseñanza, configurada a través del derecho de creación de centros docentes, la libertad de cátedra, la elección de los padres de la formación religiosa y moral para sus hijos, y la intervención de los profesores y los padres en la gestión de los centros docentes. De este análisis se ha concluido que la creación de centros docentes, el establecimiento de un ideario y la libertad de cátedra estaban sujetos al principio de rigor científico, al cumplimiento de las finalidades del artículo 27.2 CE y los planes de estudio establecidos ex artículo 27.5 CE. En contraposición, la docencia pública y la actividad educativa del Estado están sujetas al principio de neutralidad, en aras de salvaguardar el derecho de los padres del artículo 27.3 CE. Como se ha visto, en la STS 341/2009, de 11 de febrero, sobre la obligatoriedad de la Educación para la ciudadanía, la formación en valores será neutral y no supondrá una imposición ideológica siempre que se dé una exposición objetiva y plural. Este tipo de formación no da lugar al derecho de objeción de conciencia ex artículo 16.1 CE, ni circunscrito al ámbito educativo, ex artículo 27.3 CE, por lo que el citado pin parental es antijurídico. Por último, el modelo propuesto de educación de género y diversidad sexual objetivamente expuesto y sin exaltar ningún comportamiento sexual en particular coadyuva a la consecución de la finalidad de la educación, el libre desarrollo de la personalidad y el respeto de los derechos fundamentales.

En definitiva, la educación de género y diversidad sexual lejos de ser una imposición ideológica constituye una obligación constitucional. 


\section{Referencias}

\section{Legislación}

Constitución Española, 1978.

Convenio Europeo de Derechos Humanos, 1950.

Declaración Universal de Derechos Humanos, 1948.

Pacto Internacional de Derechos Económicos, Sociales y Culturales, 1966.

Pacto Internacional de Derechos Civiles y Políticos, 1966.

Ley Orgánica 5/1980, de 19 de julio, del Estatuto de los Centros docentes (DEROGADA).

Ley Orgánica 8/1985, de 3 de julio, reguladora del derecho a la educación (DEROGADA).

Ley Orgánica 1/1990, de 3 de octubre, de Ordenación General del sistema Educativo (DEROGADA).

Ley Orgánica 10/2002, de 23 de diciembre, de Calidad de la Educación (DEROGADA).

Ley Orgánica 2/2006, de 3 de mayo, de Educación (DEROGADA).

Ley Orgánica 8/2013, de 9 de diciembre, para la mejora de la calidad educativa (DEROGADA).

Ley Orgánica 3/2020, de 29 de diciembre, por la que se modifica la Ley Orgánica 2/2006 de Educación.

Ley Orgánica 3/2007, de 22 de marzo, para la igualdad efectiva de mujeres y hombres.

Ley 3/2007, de 15 de marzo, reguladora de la rectificación registral de la mención relativa al sexo de las personas.

Real Decreto 1631/2006, de 29 de diciembre, por el que se establecen las enseñanzas mínimas correspondientes a la Educación Secundaria Obligatoria (DEROGADO).

Real Decreto 1513/2006, de 7 de diciembre, por el que se establecen las enseñanzas mínimas de la Educación primaria (DEROGADO).

Ley 3/2016, contra la LGTBIfobia y la Discriminación por Razón de Orientación Sexual en la Comunidad de Madrid.

Ley 12/2015, de 8 de abril, de igualdad social de lesbianas, gais, bisexuales, transexuales, transgénero e intersexuales y de políticas públicas contra la discriminación por orientación sexual e identidad de género en la Comunidad Autónoma de Extremadura.

Ley 2/2014, de 8 de julio, integral para la no discriminación por motivos de identidad de género y reconocimiento de los derechos de las personas transexuales de Andalucía.

Ley de Vagos y Maleantes, 1933 (DEROGADA).

Ley 16/1970, de 4 de agosto, sobre peligrosidad y rehabilitación social (DEROGADA). 


\section{Jurisprudencia}

\section{Tribunal Europeo de Derechos Humanos}

STEDH 8978/80, Caso X e Y c. Reino de los Países Bajos, de 26 de marzo de 1985.

STEDH 13343/87, Caso B c. Francia, de 25 de marzo de 1992.

STEDH 53176/99, Caso Mikulic c. Croacia, de 7 de febrero de 2002.

STEDH 7525/76, Caso Dudgeon c. Reino Unido, de 22 de octubre de 1981.

STEDH 13710/88, Caso Niemietz c. Alemania, de 16 de diciembre de 1992.

STEDH 2346/02, Caso Pretty c. Reino Unido, de 29 de abril de 2002.

STEDH 6339/05, Caso Evans c. Reino Unido, de 10 de abril de 2007.

STEDH 5410/03, Caso Tysiac c. Polonia, de 20 de marzo de 2007.

SSTEDH 28957/95, Casos Christina Goodwin c. Reino Unido, de 11 de julio de 2002.

SSTEDH 79885/12, 52471/13, 52596/13, AP Caso Garçon y Nicot c. Francia, de 6 de abril de 2017.

STEDH 5095/71, Caso Kjeldsen, Busk Madsen y Pedersen, de 7 de diciembre de 1996.

STEDH 15472/02, Caso Folguero y Otros c. Noruega, de 29 de junio de 2007.

STEDH 7511/76, Caso Campbell y Cosans c. el Reino Unido, de 25 de febrero de 1982.

STEDH 21787/93, Caso Valsamis c. Grecia, de 18 de diciembre de 1996.

\section{Tribunal Constitucional}

STC 5/1981, de 13 de febrero.

STC 47/1985, de 27 de marzo.

STC 53/1985, de 11 de abril.

STC 77/1985, de 27 de junio.

STC 86/1985, de 10 de julio.

STC 120/1990, de 27 de junio.

STC 217/1992, de 1 de diciembre.

STC 57/1994, de 28 de febrero.

STC 260/1994, de 3 de octubre.

STC 36/1995, de 14 de febrero.

STC 179/1996, de 12 de noviembre. 
STC 141/2000, de 29 de mayo.

STC 154/2002, de 18 de julio.

STC 183/2008, de 22 de diciembre.

SSTC 340, 341 y 342/2009, de 11 de febrero.

STC 133/2010, de 2 de diciembre.

STC 176/2015, de 22 de julio.

STC 31/2018, de 10 de abril.

STC 99/2019, de 18 de julio.

\section{Tribunal Supremo}

STS 929/2007, de 17 de septiembre.

STS 158/2008, de 28 de febrero.

SSTS 182 y 183/2008, de 6 de marzo.

STS 731/2008, de 18 de julio.

SSTS 340,341 y 342/2009, de 11 de febrero.

STS 465/2009, de 22 de junio.

\section{Tribunal Supremo}

STSJ de Asturias 197 y 198/2008, de 11 de febrero.

SSTSJ de Andalucía 7613/2008, de 30 de abril, y 539/2008, de 4 de marzo.

SSTSJ de La Rioja 177, 196 y 197/2008.

STSJ de Madrid 1917/2008, de 6 de octubre.

STSJ de Navarra 465/2008, de 9 de octubre.

STSJ del País Vasco 835/2008, de 10 de diciembre.

\section{Obras doctrinales}

Avilés Martínez, J. M. (2002). Bullying. Intimidación y maltrato entre alumnos. Bilbao: STEE-EILAS.

Barrero Ortega, A. (2009). TEDH - Sentencias de 26.06.2007, Folgero y Otros C. Noruega, 15472/02, y de 09.10.2007, Hasan y Eylem Zengín C. Turquía, 1448/04 - Objeción de Conciencia de los padres a Educación con implicaciones morales - Enseñanza Religiosa Obligatoria. Revista de Derecho Comunitario Europeo ISSN 1138-4026, núm. 32, 259-274. 
Byrne, B. (2012). Bullies and victims in a school setting with reference to some Dublin schools. The Irish Journal of Psychology, 15(4), 574-586. https:// doi.org/10.1080/03033910.1994.10558031

Cerezo Ramírez, F. (2015). Bullying homofóbico. El papel del profesorado. International Journal of Developmental and Educational Psychology, 1(1), 417-424. https:// doi.org/10.17060/ijodaep.2015.n1.v1.45

Comisión de educación de COGAM. (2005). Homofobia en el sistema educativo. Madrid: COGAM.

Commissioner for Human Rights. (2009). Human Rights and Gender Identity. Strasbourg: Council of Europe.

Connell, R. W. (2006). Escuelas y justicia social. Madrid: Morata.

De La Mora, T., \& Terradillos, J. (2007). Reflexiones del armario. Cuadernos de Trabajo Social, 20, 249-264.

Defensor del Pueblo. (2007). Violencia escolar: el maltrato entre iguales en la Educación Secundaria Obligatoria 1999-2006. Madrid: Defensor del Pueblo.

Díez-Picazo Giménez, L. M. (2013). Sistema de derechos fundamentales (4a ed). Madrid: Civitas.

Dirección General de Servicios Sociales e Integración Social Comunidad de Madrid. (2018). Informe de incidentes de odio motivados por la LGTBfobia en la Comunidad de Madrid, 9-24.

Dworkin, G. (1997 (1988)). The theory and practice of autonomy. Nueva York: Cambridge U.P.

Fernández-Miranda Campoamor, A., \& García Sanz, R. M. (1997). Artículo 20. Libertad de expresión y derecho a la información. En Ó. Alzaga Villaamil (ed.), Comentarios a la Constitución Española de 1978, tomo II (pp. 548). Madrid: Edersa.

Fernández-Miranda Campoamor, A., \& Sánchez Navarro, Á. (1997). Artículo 27. Enseñanza. En Ó. Alzaga Villaamil (ed.), Comentarios a la Constitución Española de 1978, tomo III (pp. 243-244). Madrid: Edersa.

Generelo, J. (2016). La Diversidad sexual y de Género en el sistema Educativo: ¿qué sabemos sobre ella? Índice, 29-32.

Generelo, J., Pichardo, J. I., \& Galofré, G. (2006). Adolescencia y sexualidades minoritarias: voces desde la exclusión. Ciudad Real: Alcalá.

Gómez, E., \& Platero, R. (2007). Herramientaspara combatir el bullying homofóbico. Madrid: Talasa.

González del Valle, J. M. (1980). Libertad de cátedra y libertad de enseñanza en la legislación española. Seminario de Profesores (pp. 313-327). Pamplona: Facultad de Derecho de la Universidad de Navarra.

Herrero Brasas, J. A. (2001). La sociedad gay. Una invisible minoria. Madrid: Ediciones Foca. 
Kehily, M. J. (1999). Learning sex and doing gender: cultures of heterosexuality in the school. London: University of London.

Kehily, M. J. (2002). Issues of gender and sexuality in school. En B. Francis, \& C. Skelton (eds.), Investigating gender: contemporary perspectives in education. Buckingham: Open University Press.

Lomas, C. (2008). ¿El otoño del patriarcado? Luces y sombras de la igualdad entre hombres y mujeres. Barcelona: Península.

Merino Sancho, V. (2018). Una revisión de la jurisprudencia del Tribunal Europeo de Derechos Humanos sobre la intimidad sexual y la autonomía individual. Derechos y libertades, 38, 327-358.

Molinueva Puras, B., Martín Martín, N., \& Pichardo Galán, J. I. (2007). Actitudes ante la diversidad sexual de la población adolescente de Coslada (Madrid) y San Bartolomé de Tirajana (Gran Canaria). Madrid: Universidad Complutense de Madrid.

Molinuevo Puras, B. (2007). Especificidad del acoso escolar por homofobia. El sexo y el amor no son de un solo color. Madrid: CC. OO.

Montalvo Jääskeläinen, F. de (2018). Los Derechos y las Libertades Públicas (II). En M. I. Álvarez Vélez (ed.), Lecciones de Derecho Constitucional (pp. 418-421). Valencia: Tirant Lo Blanch.

Nogueira Soriano, R. (1988). Principios Constitucionales del Sistema Educativo Español. Madrid: Centro de Publicaciones, Ministerio de Educación y Ciencia.

Observatorio de la Juventud en España. (2010). El respeto a la diversidad sexual entre jóvenes $y$ adolescentes. Una aproximación cualitativa. Madrid: Instituto de la Juventud.

Observatorio de la Juventud en España. (2011). Jóvenes y Diversidad Sexual. Madrid: Instituto de la Juventud.

Oshana, M. (1998). Personal Autonomy in Society. Journal of Social Philosophy (Hoboken), $29(1), 82$.

Peña Calvo, J. V., \& Rodríguez Menéndez, M. D. (2002). Identidades esquemáticas de género en la escuela: a propósito del primer aniversario de la muerte de Pierre Bordieu. Teoría de la educación. Revista interuniversitaria, 14, 235-263. https://doi.org/10.14201/2998

Pichardo Galán, J. I., Stéfano Barbero, M., Faure, J., Sáenz, M., \& Williams Ramos, J. (2015). Abrazar la diversidad: propuestas para una educación libre de acoso homofóbico y transfóbico. Madrid: Instituto de la Mujer y para la Igualdad de Oportunidades.

Platero Méndez, R. (2008). La homofobia como elemento clave del acoso escolar homofóbico. Algunas voces desde Rivas Vaciamadrid. Informació psicològica, 71-83.

Rudolf, B. (2003). European Court of Human Rights: Legal status of postoperative transsexuals. International Journal of Constitutional Law, 1(4), 719-738. https:// doi.org/10.1093/icon/1.4.716 
Salguero Salguero, M. (1995). Libertad de Enseñanza, neutralidad y libertad de cátedra como formas de pluralismo institucionalizado. Derechos y Libertades: Revista del Instituto Bartolomé de las Casas, 5, 543-552.

Salvador Martínez, M. (2006). Los derechos de la educación. En S. Sánchez González (ed.), Dogmática y práctica de los derechos fundamentales (pp. 387-416). Valencia: Tirant Lo Blanch.

Secretaría de Estado de Seguridad. (2013). Informe sobre la evolución de los delitos de odio en España, 7.

Segovia, J. F. (2020). Génesis y desarrollo histórico de la autodeterminación política. Autonomía, autogobierno y autolegislación en la modernidad. En M. Ayuso Torres (ed.), La autodeterminación: problemas juridicos y politicos (pp. 17-51). Madrid, Barcelona, Buenos Aires, Sao Paulo: Marcial Pons.

Soriano Rubio, S. (2004). Como se vive la homosexualidad y el lesbianismo. Salamanca: Amaru Ediciones.

Suárez Malagón, R. (2011). Contenido y límites de la libertad de cátedra en la enseñanza pública no universitaria. Revista de Derecho UNED, 9, 421-462. https://doi.org/10.5944/ rduned.9.2011.11083

Torres Muro, I. (2012). La educación en tres momentos constitucionales (1812, 1931, 1978). Revista de pedagogía año LXX, 253, 401-416.

Torres, J. (2005). El curriculum oculto. Madrid: Morata.

Tully, J. (1995). Strange Multiplicity: Constitutionalism in an Age of Diversity. Cambridge: Press Syndicate of the University of Cambridge.

Vega Gutiérrez, A. M. (2018). La objeción de conciencia en el ámbito educativo. Los derechos fundamentales en la educación (pp. 281-282). Madrid: CGPJ.

\section{Recursos de internet}

Arpal Andreu, J. (2009, marzo 1). El devenir judicial de la asignatura de Educación para la Ciudadanía. Noticias Jurídicas. http://noticias.juridicas.com/conocimiento/articulos-doctrinales/4444-el-devenir-judicial-de-la-asignatura-de-educacion-para-la-ciudadania/ (última consulta: 09.04.2020).

Canosa Usera, R. (2003, diciembre). Sinopsis artículo 27. Obtenido de índice sistemático. Constitución española. http://www.congreso.es (última consulta: 04.04.2020).

Elvira Perales, A., \& González Escudero, Á. (2011, enero). Sinopsis artículo 20. Obtenido de índice sistemático. Constitución española. http://www.congreso.es (última consulta: 04.04.2020).

Merino Noverto, M. (2003, diciembre). Sinopsis artículo 10. Obtenido de índice sistemático. Constitución española. http://www.congreso.es (última consulta: 04.04.2020). 
VOX. (2019, mayo). Programa electoral para las elecciones autonómicas de 2019. Vox España. https://www.voxespana.es/wp-content/uploads/2019/05/Programa-Autono\%CC\%81micas-2019.pdf (última consulta: 10.04.2020). 